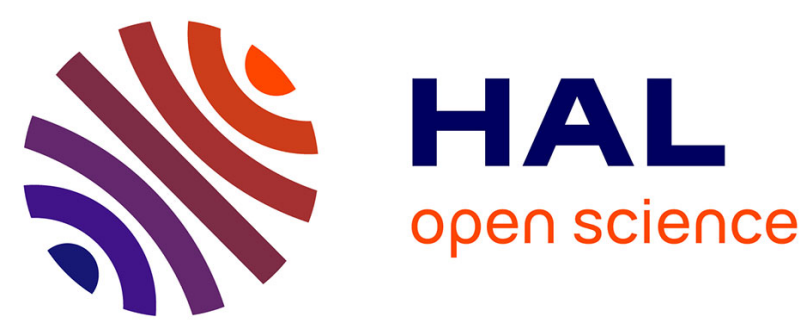

\title{
Synthesis, experimental and computational study of a non-centrosymmetric material 3-methylbenzylammonium trioxonitrate
}

Sofian Gatfaoui, Noureddine Issaoui, Thierry Roisnel, Houda Marouani

\section{- To cite this version:}

Sofian Gatfaoui, Noureddine Issaoui, Thierry Roisnel, Houda Marouani. Synthesis, experimental and computational study of a non-centrosymmetric material 3-methylbenzylammonium trioxonitrate. Journal of Molecular Structure, 2021, 1225, pp.129132. 10.1016/j.molstruc.2020.129132 . hal02932015

\section{HAL Id: hal-02932015 \\ https://hal.science/hal-02932015}

Submitted on 30 Nov 2020

HAL is a multi-disciplinary open access archive for the deposit and dissemination of scientific research documents, whether they are published or not. The documents may come from teaching and research institutions in France or abroad, or from public or private research centers.
L'archive ouverte pluridisciplinaire HAL, est destinée au dépôt et à la diffusion de documents scientifiques de niveau recherche, publiés ou non, émanant des établissements d'enseignement et de recherche français ou étrangers, des laboratoires publics ou privés. 


\title{
Synthesis, experimental and computational study of a non-centrosymmetric material 3-methylbenzylammonium trioxonitrate
}

\author{
Sofian Gatfaoui ${ }^{(a)}$, Noureddine Issaoui ${ }^{(\mathrm{b})}$, Thierry Roisnel ${ }^{(\mathrm{c})}$ and Houda Marouani ${ }^{(\mathrm{a}) *}$. \\ ${ }^{(a)}$ Université de Carthage, Faculté des Sciences de Bizerte, LR13ES08 Laboratoire de Chimie des Matériaux, \\ 7021, Bizerte, Tunisie \\ ${ }^{(b)}$ University of Monastir, Laboratory of Quantum and Statistical Physics LR18ES18, Faculty of Sciences, \\ Monastir 5079, Tunisia \\ ${ }^{(c)}$ Univ Rennes, CNRS, ISCR (Institut des Sciences Chimiques de Rennes) - UMR 6226, F-35000 Rennes, \\ France
}

*Correspondence e-mail: houdamarouani2015@gmail.com

\begin{abstract}
This paper shall address the synthesis and characterization of the novel noncentrosymmetric inorganic-organic hybrid material 3-methylbenzylammonium nitrate with general chemical formula $\mathrm{C}_{8} \mathrm{H}_{12} \mathrm{~N}\left(\mathrm{NO}_{3}\right)$ (3MBAN), this compound has been synthesized via slow evaporation method at room temperature and it is structurally characterized by singlecrystal X-ray diffraction, crystallized to the monoclinic system with space group $\mathrm{Cc}$ and the following parameters 7.574(3), 29.494(10), 5.1894(15), $\beta=128.669(11)^{\circ}, \mathrm{Z}=4, \mathrm{~V}=905.1(5)$ $\AA^{3}$ at $150 \mathrm{~K}$ and its crystal structure was determined and refined down to $\mathrm{R}=0.057$ and $\mathrm{wR}=$ 0.140. The monoprotonated 3-methylbenzylammonium cations are linked to the trigonal $\left(\mathrm{NO}_{3}{ }^{-}\right.$ ) anions by multiple bifurcated $\mathrm{N}-\mathrm{H} \ldots(\mathrm{O}, \mathrm{O})$ and weak $\mathrm{C}-\mathrm{H}$... O hydrogen bonds forming $\mathrm{R}_{4}{ }^{4}(12)$ and $\mathrm{R}_{3}{ }^{2}(6)$ motifs. The paper discusses also quantitatively the intermolecular interactions using the Hirshfeld surfaces (HS) associated with 2D fingerprint plots. The optimized molecular structure and the vibrational spectra were calculated by the density functional theory (DFT) method using the B3LYP function. Good consistency is found between the calculated results and the experimental structure; IR spectra confirmed the presence of the principal bands assigned to the internal modes of the organic cation and nitrate anion. Topological approaches such as reduced density gradient (RDG), atoms in molecules (AIM), electron localization function (ELF), endorse the occurrence of intermolecular hydrogen bonds that are responsible for the stabilization of the title compound leading to high nonlinear optical (NLO) activity. The analyses of HOMO and LUMO have been used to explain the charge transfer within the molecule. The thermal analysis of the title compound
\end{abstract}


indicates its melting at $395 \mathrm{~K}$ follows a rapid decomposition appearing around $495 \mathrm{~K}$. Finally Optical absorption reveals an important band gap energy indicating stability of the title compound.

Keywords: non-centrosymmetric, X-ray diffraction, Hirshfeld surfaces, DFT, infrared spectrum, TG-DTA.

\section{Introduction}

For several years, numerous researches have been devoted to the preparation of organic-inorganic hybrid materials [1-2]. The chemistry of these materials is arousing great interest today, because of their properties which can be valued both on the applied and on the fundamental levels. The symbiosis between two worlds of chemistry (organic and inorganic) was long considered as antagonists that can also lead to completely new properties, and open a vast field of investigation for the chemist. Indeed, the combination of the various properties of organic materials (physico-chemical, biological, etc.) and the optical, thermal and electrical properties of inorganic particles has made it possible to prepare many materials for different practical fields especially: biology, pharmacology, optics, adhesives, surface modification, membranes [3-8]. Particularly the interaction of nitric acid with organic entities, the object of our work, gives rise to organic nitrates having important properties in biological systems namely, 1-methylpiperazine-1,4-diium bis(nitrate) [9], 1H-1,2,4-triazole-4-ium trioxonitrate [10], 1-ethylpiperazine-1,4-diium bis(nitrate) [11], Theophyllinium Nitrate [12] and pharmaceutical systems as in the case of glyceryl trinitrate, Indeed their measurement of plasma concentrations is very difficult, as Bogaert mentions [13]; also nitrates penetrate biological treatment systems or as pharmacological products [14-18]. Recently, the variety of semi organic crystals has been developed for non-linear optical applications. The insertion of organic cations into an inorganic matrix could lead to non-centrosymmetric arrangements active in non-linear optics, like Bis(glycine) lithium nitrate [19]. The present research has successfully synthesized a new organic nitrate called 3-methylbenzylammonium nitrate (3MBAN). This compound is studied by X-ray diffraction, as it is the main technique used in first stage to obtain information on the crystallographic characteristics and in a second stage to determine the atomic parameters and the arrangement atoms in crystal lattices. Along with this work material is associated with a study by molecular modeling. The main objective of this modeling is to optimize the structure and to determine its geometric parameters in order to compare them with those obtained experimentally. This modeling is carried out by the method of the density functional theory (DFT) with the functional B3LYP using the base 6- 
$311 \mathrm{G}(\mathrm{d}, \mathrm{p})$. Also a computational analysis was used to quantify the different interactions already observed by X-ray diffraction; it is the Hirshfeld surfaces (HS) analysis which shows the great occupation of the $\mathrm{H} \ldots \mathrm{H}$ and $\mathrm{O} \ldots \mathrm{H} / \mathrm{H} \ldots \mathrm{O}$ contacts on this surface. Other topological analyzes were planned including AIM, RDG, ELF, NLO. The thermolysis of 3MBAN compound was carried out using differential thermal (DTA) and thermogravimetric (TG) analysis which shows its total decomposition into $750 \mathrm{~K}$. The synthesized compound was also characterized by infrared and ultraviolet-visible absorption spectroscopic methods.

\section{Experimental}

\subsection{Synthesis and crystallization}

A stoichiometric amount of 3-methylbenzylamine dissolved in ethanol is added drop wise to an aqueous solution of nitric acid. The obtained solution reaches a $\mathrm{pH}$ close to seven, and at the end of reaction the product is left in the open air, until the appearance of the crystals. The equation for the synthesis reaction that occurs is as follows:

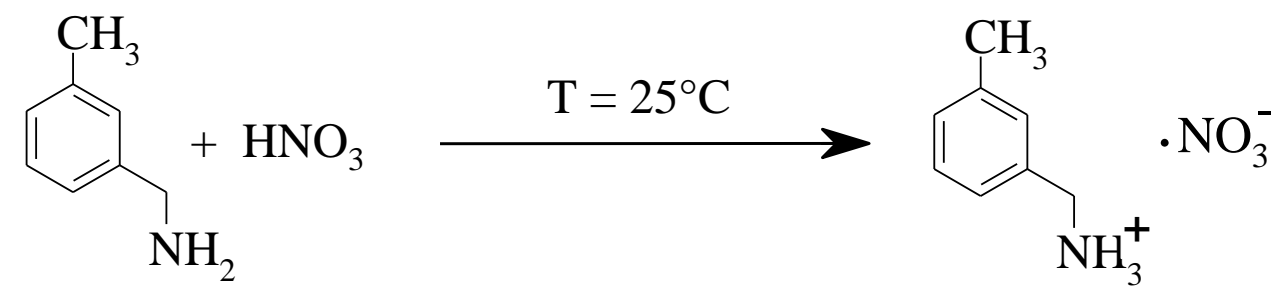

The single crystals collected have the colorless prismatic form, stable at room temperature and of sufficient size for a structural study.

\subsection{Materials and physical measurements}

Measurements of X-ray diffracted intensities were recorded at $150 \mathrm{~K}$ using a diffractometer Bruker-AXS APEXII, working at molybdenum wavelength $(\lambda=0.71073 \AA)$. Absorption corrections were carried out by the multi-scan technique by means of SADABS program [20]. Among the 2217 reflections measured only 1281 are independent and 1020 had intensity I $>2 \sigma(\mathrm{I})$. The direct methods using the SIR97 program were employed to solve the structure [21], then, refined with full-matrix least-square methods based on $\mathrm{F}^{2}$ (SHELXL-97) [22] through the assist of the WINGX program [23]. All non-hydrogen atoms were refined by means of anisotropic atomic displacement parameters. All the hydrogen atoms linked to carbon atoms were located in calculated positions and refined by fixed individual displacement parameters awarded to the riding model $(\mathrm{C}-\mathrm{H}$ (aromatic, methylene, methyl) bond lengths of $0.95 \AA, 0.99 \AA$ and $0.98 \AA$, respectively). The remained hydrogen atoms linked to nitrogen atoms were positioned geometrically and allowed to ride on their parent atoms, with $\mathrm{N}-\mathrm{H}=0.91\left[\mathrm{U}_{\text {iso }}(\mathrm{H})=1.5 \mathrm{U}_{\text {eq }}\right]$. A final refinement on $\mathrm{F}^{2}$ converged at $\mathrm{R}\left(\mathrm{F}^{2}\right)=$ 
0.057 and $w R\left(F^{2}\right)=0.140$. Structure graphics are drawn with ORTEP [23] and Diamond program [24]. IR spectrum was recorded in the range $4000-400 \mathrm{~cm}^{-1}$ with a NICOLET IR 200 FT-IR infrared spectrometer. The spectral resolution was $4 \mathrm{~cm}^{-1}$. Thermal analysis was performed using a multimodule 92 Setaram analyzer operating from room temperature up to $880 \mathrm{~K}$ at an average heating rate of $5 \mathrm{~K} / \mathrm{min}$ and the mass of the simple was $9.4 \mathrm{mg}$ for TG /DTA. UV-Vis spectrum was recorded on a Perkin-Elmer Lambda 19 spectrophotometer in the 200-800 $\mathrm{nm}$ range. The spectral resolution was $2 \mathrm{~nm}$.

\subsection{Theoretical studies}

Hirshfeld surface analysis (HS) is a study based on a three dimensional graphics used for the visualization and understanding of intermolecular interactions. The analysis and calculations were carried out using the Crystal Explorer version 3.1 [25] software imported on a CIF file. The molecular geometry optimization and all quantum chemical calculations have been performed by using the hybrid B3LYP/6-311++G (d,p) method with the Gaussian 09 software package [26] and the GaussView molecular visualization program [27]. In this study, the topological properties were determined with the Multiwfn program [28] in accordance with the Bader's theory [29]. RDG-NCI analysis was performed using Multiwfn multifunctional wave function analyzer [28] and plotted using VMD molecular visualization program [30]. The vibrational assignments were performed considering the potential energy distribution components (PED) $\geq 10 \%$ using the VEDA4 package [31]. The GaussView molecular visualization program [27] was used to verify the assignments of the bands.

\section{Results and discussion}

\subsection{X-ray diffraction and molecular modeling}

The ORTEP representation of 3-methylbenzylammonium nitrate (Fig. 1a) made it possible to establish the structural model, whose asymmetric unit consists of a monoprotonated organic cation which is 3-methylbenzylammonium (3MBA) and a mineral anion $\left(\mathrm{NO}_{3}{ }^{-}\right)$. The junction between the two anionic and cationic entities is ensured by medium N-H ... O hydrogen bonds and C-H ... O weak interactions. To describe the atomic arrangement of this structure, it has been projected it in the two $\vec{a}$ and $\vec{c}$ directions. Fig. $2 \mathrm{a}$ shows the distribution of organic cations in zigzag along $\vec{b}$ in position $\mathrm{y}=0$ and $\mathrm{y}=1 / 2$ between which the nitrate anions are inserted in position $y=1 / 4$ and $y=3 / 4$ by establishment of $\mathrm{N}-\mathrm{H} \ldots \mathrm{O}$ and $\mathrm{C}-\mathrm{H} \ldots \mathrm{O}$ hydrogen bonding. In the anionic entity $\mathrm{NO}_{3}{ }^{-}$the lengths and angles of interatomic bonds are distributed respectively in the ranges 1.236(5)-1.253(5) $\AA$ and 117.9(4) $-121.7(4)^{\circ}$. These geometrical characteristics listed in Table 2 were also compatible with those encountered in other organic nitrates [32-36]. Concerning the cationic entity 3- 
methybenzylammonium, the set of geometric parameters describing the latter are illustrated in Table 2. Indeed, the aryl group has a plane geometry disubstituted in C3 and C5 position, a methyl $\left(-\mathrm{CH}_{3}\right)$ coplanar with the phenyl group on the $\mathrm{C} 2$ atom and a group $\left(-\mathrm{CH}_{2}-\mathrm{NH}_{3}\right)$ on the $\mathrm{C} 5$ atom. The aromatic nucleus is characterized by $\mathrm{C}-\mathrm{C}$ bond lengths varying from $1.376(3)$ to $1.384(3) \AA$ with an average value $\langle\mathrm{C}-\mathrm{C}\rangle=1.38 \AA$ and $(\mathrm{C}-\mathrm{C}-\mathrm{C})$ bond angles around $120^{\circ}$ confirming the good flatness of the cycle with a mean plane deviation of 0.0045 $\AA$. The (C2-N1, C3-C2, C5-C9) distances vary from 1.476(5) to 1.504(6) $\AA$. The C4 - C3 $\mathrm{C} 2, \mathrm{C} 4-\mathrm{C} 5-\mathrm{C} 9, \mathrm{C} 8-\mathrm{C} 3-\mathrm{C} 2$ and $\mathrm{C} 6-\mathrm{C} 5-\mathrm{C} 9$ angles range from 119.5(4) to 121.6(4) ${ }^{\circ}$. The $\mathrm{N}$ atom of the 3-methylbenzylammonium cation is displaced by 1.252 (2) $\AA$ from the mean plane of the other atoms and forms with its three hydrogen atoms a regular tetrahedron with bond angles around $109.5^{\circ}$. These geometric quantities are comparable to those encountered in other similar structures [32, 37].

The crystal structure of $3 \mathrm{MBAN}$ compound is mainly constructed on the basis of a network of moderate hydrogen bonds of $\mathrm{N}-\mathrm{H} \ldots \mathrm{O}$ type and weak of $\mathrm{C}-\mathrm{H} \ldots \mathrm{O}$ type with donor-acceptor distances varying from $2.848(5)$ to 3.398(6) $\AA$ (Table 3). The N-H...O bonds are mainly present in $3 \mathrm{MBAN}$ and play an important role in maintaining the crystal structure of the compound thanks to the cycles formed by their combinations. Indeed each ammonium group is engaged with four nitrate anions forming a hydrogen bonding network in the form of glasses superimposed in parallel generating $\mathrm{R}_{4}{ }^{4}(12)$ and $\mathrm{R}_{3}{ }^{2}(6)$ patterns (Fig. 3).

A comparison of 3MBAN (I) to 4-methylbenzylammonium nitrate (II) [32] shows they differ only by position of $\mathrm{CH}_{3}$ and $\mathrm{CH}_{2} \mathrm{NH}_{3}$ on the phenyl ring. However, some similarities can be observed between these structures. In each of these cases, they have two dimensional network. Likewise as in (I), the asymmetric unit of (II) consists of the organic cation and the nitrate anion, connected by moderate N-H... O hydrogen bonds. However, the structure (I) crystallizes in the non centrosymmetric Cc space group and the structure (II) crystallizes in the centrosymmetric $\mathrm{P} 2{ }_{1} / \mathrm{c}$ group. As a result, in structure (II) organic groups are organized in similar direction and in opposition, thus creating a local inversion center, which is not the case with the 3-methylbenzylammonium groups in structure (I).

Previous studies have shown that DFT calculations using the B3LYP functional associated with the $6-311++\mathrm{G}(\mathrm{d}, \mathrm{p})$ base lead to predictions of molecular structures similar to those given by experience. So using the DFT-B3LYP/6-311++G (d,p) method, the 3MBAN structure which is illustrated in Fig. 1b has been optimized. The different structural parameters calculated by this method of 3MBAN are compared to those found by X-ray diffraction and given in Table 2. The lengths of $\mathrm{C}-\mathrm{C}$ bonds (forming the benzene ring) and 
the $\mathrm{C}-\mathrm{C}-\mathrm{C}$ angles (forming the benzene ring and outside the aromatic nucleus) are respectively in the vicinity of $1.40 \AA$ and $120^{\circ}$. The $\mathrm{C} 5-\mathrm{N} 1, \mathrm{C} 8-\mathrm{C} 5$ and $\mathrm{C} 11-\mathrm{C} 18$ distances calculated are around $1.50 \AA$. The calculated connection $\mathrm{C}-\mathrm{C}-\mathrm{N}$ angle is equal to $111.1644^{\circ}$. The theoretical results attributed to the cationic group are slightly elongated (0.01) compared to those experimental. Concerning the nitrate anion, the N22-O23 and N22-O24 distances calculated show no particularities with respect to those obtained by X-ray diffraction as long as $\mathrm{N} 22-\mathrm{O} 25$ is lengthened by $0.06 \AA$ compared to the experimental one. This could be explained by the engagement of the oxygen atom $\mathrm{O} 25$ in a hydrogen bond N1-H4... 225 . In conclusion these theoretical deviations are explained by the fact that the calculations are carried out in the gas phase while the experimental structure is measured in the crystalline phase.

\subsection{Hirshfeld surface investigation $(H S)$}

Hirshfeld surfaces (HS) (3D) and two-dimensional fingerprints were performed with Crystal Explorer 3.1 software [25] imported into CIF files. Indeed, these two approaches give the possibility of obtaining a qualitative and quantitative overview of the nature of intermolecular interactions in crystal structures. The maps (3D) in " $d_{n o r m}$ " and " $d_{e}$ " and the fingerprint (2D) of the various contacts existing in the 3MBAN structure are displayed in Fig. 4. The examination of the mode of $d_{\text {norm }}$ (Fig. 4a) and $d_{e}$ (Fig. 4b) representations of the elaborated compound makes it possible to highlight the presence of close contacts taking place between the oxygen and hydrogen atoms responsible for the formation of $\mathrm{N}-\mathrm{H} \ldots \mathrm{O}$ hydrogen bonds at the red and orange spots indicated respectively by the label (1) on the two three-dimensional maps $d_{n o r m}$ and $d_{e}$. Concerning the blue color (label (2)) observed on large areas of $d_{n o r m}$ and in the form of small spots on the $d_{e}$ graph, the use of this color is an indicator that there is absence of close contacts in this region seen the too great distance separating neighboring atoms from an intermolecular point of view and the presence of distant contacts such as H... H, C... H, N... H... [38-40]. The $d_{i}$ and $d_{e}$ combination in the twodimensional fingerprint plot (Fig. 4c) provides a summary of the intermolecular contacts that exist in our crystal. The H... H contacts appear as a symmetrically dispersed point covering a large region of the plot with two neighboring peaks very close $d_{e}=d_{i} \sim 1.1 \AA$, with a large occupation of the entire Hirshfeld area $(40.2 \%$ (Fig. 5)). The O...H/H... contribution, corresponding to the $\mathrm{N}-\mathrm{H} \ldots \mathrm{O}$ and $\mathrm{C}-\mathrm{H}$... O interactions, are represented by a pair of sharp points characteristic of the hydrogen bonds having almost the same $d_{e}+d_{i} \sim 1.9 \AA$. Note that the proportions of $\mathrm{O} \ldots \mathrm{H}$ and $\mathrm{H} \ldots \mathrm{O}$ interactions are not similar $(\mathrm{O} \ldots \mathrm{H}(20.1 \%)$ and $\mathrm{H} \ldots \mathrm{O}$ $(17.4 \%))$. The pair of separate wings is assigned to the C...H/H...C contacts with a $16.3 \%$ 
stake in the Hirshfeld area $\left(d_{e}+d_{i} \sim 2.8 \AA\right)$. Among these three contacts only the oxygenhydrogen contacts are considered close together with a sum $d_{e}+d_{i}$ less than the sum of the Van der Waals radii of the involved atoms $(\mathrm{H}: 1.09 \AA$, O: $1.52 \AA)$. The rest of contacts, namely $\mathrm{N} \ldots \mathrm{O} / \mathrm{O} \ldots \mathrm{N}, \mathrm{O} \ldots \mathrm{O}, \mathrm{C} \ldots \mathrm{O} / \mathrm{O} \ldots \mathrm{C}$ and $\mathrm{N} \ldots \mathrm{H} / \mathrm{H} \ldots \mathrm{N}$ only participates with $6.1 \%$ on the HS. These contacts are classified with the H...H and C...H/H...C contacts in the category of distant contacts which have a summation $d_{i}+d_{e}$ greater than the sum of the van der Waals radii of considered atoms. A further analysis of HS was conducted using a new descriptor, the enrichment ratio ER [41]. This ratio is defined as being the ratio between the percentage of real contacts in the crystal and the theoretical percentage of random contacts. The enrichment ratio (ER) values are summarized in Table 4. The list of enrichment ratio highlights the oxygen-hydrogen contacts $\left(\mathrm{ER}_{\mathrm{OH}}=1.24\right)$ which appear to be favored in crystal packaging with the formation of $\mathrm{N}-\mathrm{H} \ldots \mathrm{O}$ and $\mathrm{C}-\mathrm{H} \ldots \mathrm{O}$ hydrogen bonds. The C...H/H...C contacts are slightly favored in a sample which contains aromatic molecules with an average value of $\mathrm{ER}_{\mathrm{CH}}=1.42 . \mathrm{H} \ldots \mathrm{H}$ contacts comprise $40.2 \%$ of the HS. This value becomes much lower by adding to the value calculated for the random contacts (67.4\%) so that these contacts adopt an enrichment ratio far from the unit (0.60). The enrichment ratio values of other contacts are of little significance because of their small contributions to the global HS [10].

\subsection{Thermolyses of $3 M B A N$ compound}

To better understand the behavior of $3 \mathrm{MBAN}$ taking temperature into account, a thermal study was carried out on a mass sample $9.4 \mathrm{mg}$ in an argon atmosphere, with a heating rate of $5 \mathrm{~K} \cdot \mathrm{min}^{-1}$ of the ambient temperature up to $880 \mathrm{~K}$. The differential thermal and thermogravimetric analysis curves of 3MBAN are given in Fig. 6. The DTA curve shows the presence of a fine endothermic peak located at $395 \mathrm{~K}$ without any loss of mass observed by the TG curve. To better understand the nature of this phenomenon or this transformation, the starting product was heated to a temperature slightly below $395 \mathrm{~K}$ for a few minutes on a kofler bench, which leads to the melting of our product and to the start of its decomposition. Then after a $100 \mathrm{~K}$ temperature we observe a second exothermic peak at $495 \mathrm{~K}$. This peak is accompanied, on the TG curve, by a large loss of mass which corresponds to the total decomposition during which the compound undergoes an inflammation and explosion leading to the end of the handling of nitrogen oxides $\left(\mathrm{NO}, \mathrm{NO}_{2}\right)[\mathbf{9}, \mathbf{1 0}, \mathbf{3 8}]$. Other previous thermal studies $[42,43]$ carried out on this type of material show that these phenomena correspond to a thermal decomposition process which takes place in two stages, a first stage during which a proton transfer between ammonium ion and nitrate anion has been observed in a condensed phase and at a higher temperature which causes an internal redox reaction (ORR) between the 
amine and acid, leading to the ignition of the material. A second step corresponds to the rest of the decomposition mechanism which has not yet been defined in a unique way and different reactions can be expected. The diagram below summarizes the thermal decomposition of $3 \mathrm{MBAN}$ material:
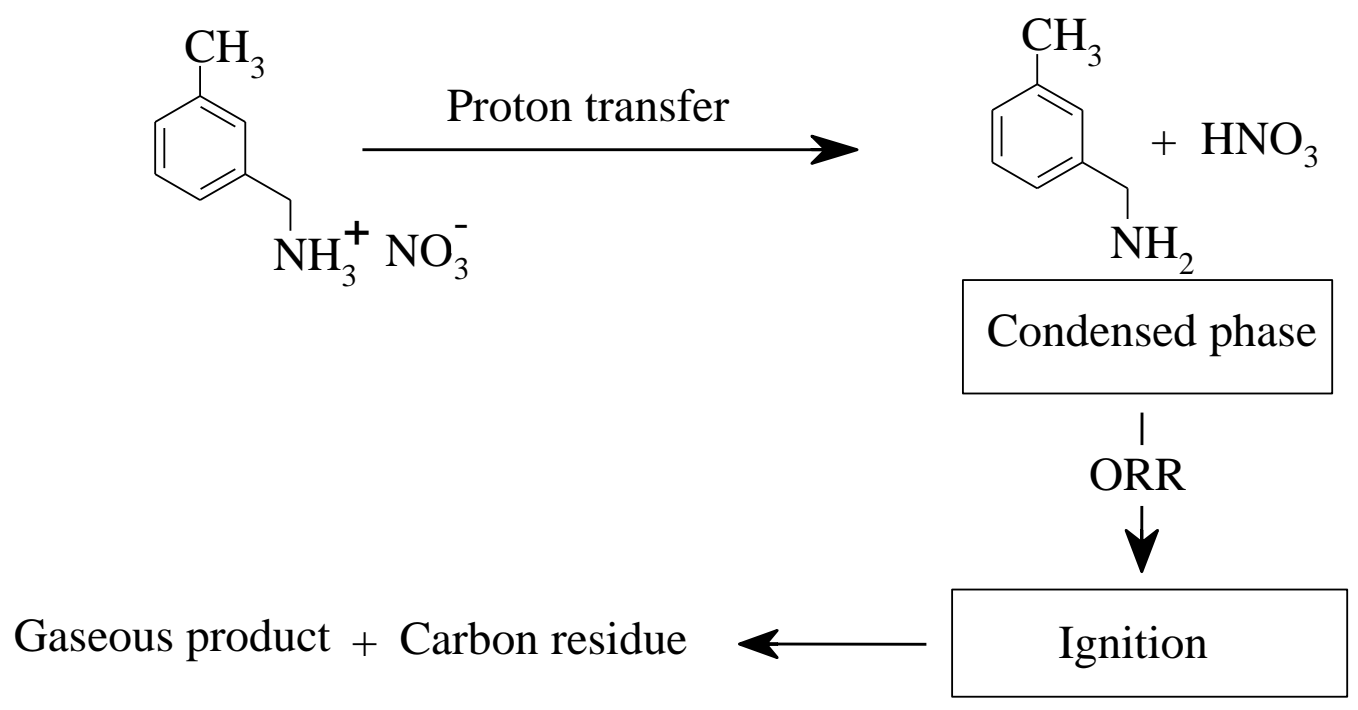

\subsection{Quantum theory of atoms in molecules (QTAIMs) analysis}

Several theoretical studies, especially Bader's quantum theory [29] make it possible to characterize the nature of interatomic interaction between two involved atoms, the nonbinding interactions, the electronic structure and the chemical reactivity of the molecule, from the different properties, topological (electronic density $\rho$, Laplacian $\nabla^{2} \rho$, Hessian eigenvalues $\lambda_{\mathrm{i}}(\mathrm{i}=1,2,3)$ ), energetic (the kinetic energy densities $\mathrm{G}$, potential $\mathrm{V}$ and total $\mathrm{H}=\mathrm{G}+\mathrm{V}$ ) as well as the electronic distribution. In addition, the Laplacian of electronic density $\nabla^{2} \rho(r)$ at the critical point BCP is a powerful tool in the characterization of the bond zones. Hence the charge concentration zones are characterized by $\nabla^{2} \rho(r)<0$ and those of charge depletion have $\nabla^{2} \rho(r)>0$. Indeed $\rho(r)$ and $\nabla^{2} \rho(r)$ at the critical points were used to evaluate the bonds properties in the studied compounds, in particular the hydrogen bonds. Therefore Koch and Popelier [44] confirm the existence of a hydrogen bond by:

- The presence of a BCP between the hydrogen atom of the donor group and the acceptor group.

- $\quad \rho(\mathrm{BCP})$ at BCP, should be low and in the range 0.0020-0.0400 a.u.

- $\nabla^{2} \rho(\mathrm{BCP})>0$ and located in the range $0.0240-0.1390$ a.u.

On the other hand to classify these hydrogen bonds Rozas et al. [45] propose the following three criteria: 
- A hydrogen bond considered strong if and only if $\nabla^{2} \rho(\mathrm{r})<0$ and $\mathrm{H}(\mathrm{r})<0$.

- A hydrogen bond is said to be average if and only if $\nabla^{2} \rho(\mathrm{r})>0$ and $\mathrm{H}(\mathrm{r})<0$.

- A hydrogen bond classified as weak if and only if $\nabla^{2} \rho(r)>0$ and $\mathrm{H}(\mathrm{r})>0$.

The graphical representations of AIM analysis of 3MBAN monomer and dimmer are shown respectively in Figs. 7a, 7b while the topological parameters obtained are grouped in Table 5. Inspection of the table shows that critical points BCPs located at the $\mathrm{O} \cdots \mathrm{H}$ bonds of the monomer and the dimmer are characterized by a low electron density and a positive Laplacian. For the monomer conformation, $\rho(\mathrm{BCP})$ at the level of $\mathrm{H} 4 \ldots \mathrm{O} 25$ equal to 0.0237 a.u. while Laplacian is of the order of 0.0784 a.u.. Concerning the dimmer conformation the electronic densities located at the level of the O... H bonds are: 0.0233 a.u. (O46 ... H4), 0.0051 a.u. (O44... H31), 0.0074 a.u. (O44 ... H27), 0.0141 a.u. (O50 ... H2), 0.0047 a.u. (O50 ... H17) and 0.0229 a.u. (O50 ... H24) connections with Laplacian values of 0.0814, 0.0166, 0.0250, 0.0507, 0.0171, 0.0800 a.u., respectively. Positive Laplacian values indicate depletion of electronic charge along the bond path. Note that all these values are in agreement with the Koch and Popelier criteria. The AIM analysis of the monomer and dimmer of the studied compound comes to the conclusion that formation of the dimmer manifests itself by a decrease in the electron density at the BCPs located at the O...H bonds. This reduction is explained by the transfer of charges from the acceptor proton to donor proton of $\mathrm{O} \ldots \mathrm{H}$ binding. According to Rozas et al. the hydrogen bonds existing in the monomer and the dimmer such as $\mathrm{N} 1-\mathrm{H} 4 \ldots \mathrm{O} 25, \mathrm{~N} 1-\mathrm{H} 4 \ldots \mathrm{O} 46, \mathrm{~N} 1-\mathrm{H} 2 \ldots \mathrm{O} 49, \mathrm{C} 16-\mathrm{H} 17 \ldots \mathrm{O} 49, \mathrm{C} 26$ $-\mathrm{H} 27 \ldots \mathrm{O} 44$ and $\mathrm{C} 30-\mathrm{H} 31 \ldots \mathrm{O} 44$ are classified as weak with a Laplacian $\nabla^{2} \rho(\mathrm{r})$, a total energy density $\mathrm{H}(\mathrm{r})$ greater than zero and also with ratios $|\lambda 1 / \lambda 3|$ greater than unity. The energy of hydrogen bond can be calculated using the relationship deduced by Espinosa et al. [46] $\left(\mathrm{E}_{\mathrm{HB}}=\mathrm{V}(\mathrm{r}) / 2\right)$. In the two monomeric and dimeric cases of $3 \mathrm{MBAN}, \mathrm{E}_{\mathrm{HB}}$ corresponds to $\mathrm{O} \ldots \mathrm{H}$ is very weak and is less than zero; this allowed us to affirm that hydrogen bonds are weak. In addition, the AIM analysis detecting the presence of RCP and NRCP critical points respectively at the level of aromatic nuclei of 3-methylbenzylammonium cations and at the level of new cycles closed by hydrogen bonds. The presence of RCP critical point in the cycle confirms the cyclical nature of an atomic chain. Note that $\rho(r)$ electronic densities and the $\nabla^{2} \rho(\mathrm{r})$ Laplacian at the RCP, RCP1 and RCP3 point at the level of the monomer and the dimmer have mean values $\langle\rho(r)\rangle=0.0223$ a.u. and $\left\langle\nabla^{2} \rho(r)\right\rangle=0.1660$ a.u.. These values are higher than those observed at the NRCP points, which clearly explains the great stability of the aromatic cycle of the 3-methylbenzylammonium group. 
The reduced density gradient (RDG) abbreviation is a new topological descriptor proposed by Johnson et al. [47] to study the different interactions within molecular structures. It makes it possible to identify the regions of weak interactions in real space based on the density of electrons and its first derivative:

$$
R D G(r)=\frac{1}{2\left(3 \pi^{2}\right)^{1 / 3}} \frac{|\nabla \rho(r)|}{\rho(r)^{4 / 3}}
$$

The graphic cards shown in Fig. 8 show the reduced density gradient (RDG) as a function of ( $\left.\rho^{*} \operatorname{sign} \lambda_{2}\right)$ and the isosurface density (with $\lambda_{2}$ the second eigenvalue of the Laplacian density) of the monomer (a) and dimeric (b) conformation of 3MBAN material. The sign of $\lambda_{2}$ is used to distinguish linked interactions $\left(\lambda_{2}<0\right)$ from unbound interactions $\left(\lambda_{2}>0\right)$. So $\operatorname{sign} \lambda_{2}<0$ (hydrogen bonds), $\operatorname{sign} \lambda_{2}>0$ (repulsive contributions) and the values located near the separation (close to zero) are attributed to the van der Waals interactions. In the RDG graph (monomer and dimer) of the 3MBAN compound, the crystalline stability of our molecule is ensured by hydrogen bonds of $\mathrm{N}-\mathrm{H}$...O and $\mathrm{C}-\mathrm{H}$...O type which are located in the $\operatorname{sign}\left(\lambda_{2}\right) \rho[-$ 0.015 to $-0.005 \AA$ ] interval. Different interaction regions are identified by three-dimensional RDG isosurfaces (Fig. 8b) according to a well-defined color code. The blue spots interspersed between the oxygen atoms proton acceptor of $\left(\mathrm{NO}_{3}{ }^{-}\right)$group and the hydrogen atoms signify a strong interactive interaction attributed to the hydrogen bonds $\mathrm{N}-\mathrm{H} \ldots \mathrm{O}$, while the green spots correspond to the van der Waals interactions and the elliptical red spots located at the level of the aromatic cycles show a strong steric effect.

\subsection{Electron localization function analysis}

The electron localization function analysis (ELF) provides the description of chemical structure. It generally gives information on the nature of the interactions and the reactivity of molecule by observing the order of separation of the domains varying between 0 and 1 :

- ELF values close to 1 correspond to well-localized electrons (regions of maximum Pauli repulsion).

- ELF values near 0 are assigned to regions of minimum Pauli repulsion.

Using Multiwfn program the two-dimensional graphical maps of monomer and dimmer conformations of the 3MBAN compound were recorded in Figs. 9a and 9b, respectively. Indeed the clouds formed by black lines observed on the cartography presented in Fig. 10 prove a decrease in the electron density. The high ELF values (Fig. 9) (About 0.8-1.0) are colored in red. The series goes from yellow to green and is relative to the average ELF values (about 0.5 ) while the lower end of the scale represented by the dark blue color revealed a decrease in ELF in the corresponding regions. In conclusion, the red regions surrounded by 
hydrogen atoms with a single electron are the strongest with maximum Pauli repulsion, while the other blue areas were occupied by the nitrogen atom of nitrate group and the carbon atoms of the organic cation with similar spin electrons from which the electrons close with minimal Pauli repulsion.

\subsection{Non-linear optical properties study}

Nonlinear optics groups together all of the optical phenomena presenting a nonlinear response with respect to the electric field $(\vec{E})$. The origin of non-linear effects lies in a strong interaction between the light wave and the material it crosses. Application of an electric field on a material medium produces a displacement of the electronic orbits of atoms compared to the nuclei; so the medium is polarized. Polarizability and hyperpolarizability characterize the response of a system to the applied electric field [48] and determine the cross sections of the different diffusion and collision processes, as well as the nonlinear optical properties of the system $[49,50]$. In the presence of a uniform electric field, the energy of a system can develop in Taylor series compared to an electric field:

$$
E(F)=E_{0}-F_{i} \mu_{i}-\frac{1}{2} \alpha_{i j} F_{i} F_{j}-\frac{1}{6} \beta_{i j k} F_{i} F_{j} F_{k^{-}} \ldots
$$

With $E_{0}$ is the energy of the undisturbed system. $F_{i}$ is the field originally. $\mu_{i}, \alpha_{i j}$ and $\beta_{i j k}$ are the components of dipole moment, first-order polarizability and hyperpolarizability respectively. Indeed the dipole moment $\mu$, the average polarizability $\alpha$, and the total static hyperpolarizability $\beta$ of $3 \mathrm{MBAN}$ are calculated using the method B3LYP/6-311++G(d,p) and grouped in Table 6. The quantities cited in the previous table are obtained from the following equations:

$$
\begin{gathered}
\mu=\left(\mu_{x}{ }^{2}+\mu_{y}{ }^{2}+\mu_{z}{ }^{2}\right)^{1 / 2} \\
\alpha_{t o t}=\frac{1}{3}\left(\alpha_{x x}+\alpha_{y y}+\alpha_{z z}\right) \\
\beta=\left[\left(\beta_{x x x}+\beta_{x y y}+\beta_{x z z}\right)^{2}+\left(\beta_{y y y}+\beta_{y z z}+\beta_{y x x}\right)^{2}+\left(\beta_{z z z}+\beta_{z x x}+\beta_{z y y}\right)^{2}\right]^{1 / 2}
\end{gathered}
$$

The values of the dipole moment, the polarizability and the first order hyperpolarizability $\beta_{\text {tot }}$ calculated are respectively $14.38 \mathrm{D}, 17.39 \times 10^{-24} \mathrm{esu}, 5252.35 \times 10^{-33}$ esu. The comparison of these values with the values of these relative parameters of the urea $(\mu=1.3732$ Debye, $\alpha=$ $5.0477 \times 10^{-24} \mathrm{esu}, \beta=372.8 \times 10^{-33} \mathrm{esu}$ ) which is a standard NLO reference material shows the large value $\beta$ which is equal to $14 x \beta_{\text {urea }}$ indicating second order optical effects for the potential of 3MBAN. The dipole moment has a very high value, $10 x \mu_{\text {urea }}$, which explains the noncentrosymmetric nature of this molecule and the polarizability is higher than that of urea (more than $3 \alpha_{\text {urea}}$ ). Hydrogen bonds play a very interesting role in stabilizing the crystal structure but more obviously they also contribute considerably to the improvement of the 
hyperpolarizability of molecular systems linked to hydrogen or to the improvement of the second-order susceptibility of crystals. Therefore According to the recently published literature [51-52], these results conclude that the 3MBAN is a good candidate of material which can have an industrial application on nonlinear optics (NLO).

\subsection{Frontier molecular orbital analysis}

The spatial distribution of molecular orbitals, in particular the boundary orbitals, HOMO (Highest Occupied Molecular Orbital) and LUMO (Lowest Unoccupied Molecular Orbital), are excellent indicators of electron transfer in molecular systems. HOMO is the orbital which acts mainly as an electron donor and LUMO is the orbital which acts largely as an electron acceptor. The gap energy $\Delta \mathrm{E}$ is defined as the difference between the energy of the HOMO and LUMO orbital's, $\mathrm{E}_{\mathrm{LUMO}}-\mathrm{E}_{\mathrm{HOMO}}$. This energy quantity is used to characterize the chemical reactivity and the kinetic stability of the molecule. Indeed when the gap energy $\Delta \mathrm{E}$ is high, the flow of electrons in the higher energy states is difficult, which makes the molecule hard and less reactive. On the other hand, the lower gap energy $\Delta \mathrm{E}$ results in an easy flow of electrons, making the molecule soft with a high reactivity criterion. Besides gap energy, hardness and chemical softness are also good indicators of the chemical stability of a molecule. Another important electronic property for a molecule is the dipole moment. All the previously mentioned quantities and other quantum parameters (electronegativity and electrophilic index) are calculated using the DFT method B3LYP/6-311++G(d,p) and presented in Table 7. The HOMO, LUMO border orbital's involved in the electronic transitions of the studied molecule, are shown in Fig. 11. The energy difference between HOMO and LUMO is around $5.34 \mathrm{eV}$. This important value implies a high kinetic stability and low chemical reactivity for the 3MBAN compound. The stereographs of the molecular boundary orbital of our material show that the HOMO components are concentrated and localized on the organic matrix, while the LUMO components are mainly located on the nitrate anion. These results suggest the delocalization of electrons in the organic part. Note that different parameters mentioned above in Table 7 are calculated starting from the energies of HOMO and LUMO border orbital. So the energies of HOMO and LUMO border orbital's of the studied compound are related to the ionization potential I and the electronic affinity A, respectively, by the following relationships: $\mathrm{I}=-\mathrm{E}_{\mathrm{HOMO}}$ and $\mathrm{A}=-\mathrm{E}_{\mathrm{LumO}}$. The electronegativity $(\chi)$, hardness $(\eta)$, softness $(S)$, electrophilicity index $(\psi)$ and the chemical potential $(\mu)$ are defined respectively as follows: $\chi=\frac{I+A}{2} \quad$ (defined by Mulliken [53]), $\eta=\frac{I-A}{2}$ (A hard molecule has a large gap energy [54]), $S=\frac{1}{\eta} \quad$ (A soft molecule has a low gap energy 
[54]), $\Psi=\frac{\mu^{2}}{2 \eta}$ (A good nucleophile is characterized by weak $\psi$, and vice versa defined by Parr et al. [55]) et $\mu=-\frac{I+A}{2}$. To conclude, in the gaseous phase the compound object of this study has a hardness equal to $2.67 \mathrm{eV}$ and a chemical softness equal to $0.38 \mathrm{eV}$. The electrophile index $\psi=3.68 \mathrm{eV}$ is relatively high, so $3 \mathrm{MBAN}$ can be considered a good electrophile. $\mu<0$, this means that the structure is stable and biologically active and does not spontaneously break down into its elements [56]. It is worth noting that these results are similar to those found in other organic nitrates [10, 39].

\subsection{Vibrational spectroscopic study}

A spectroscopic infrared absorption study was carried out along this work which permits to determine the vibrational characteristics of the atomic groupings of the produced compound as well as the enumeration of the vibration modes and the allocation of the absorption bands of the nitrate anion $\left(\mathrm{NO}_{3}{ }^{-}\right)$and 3-methylbenzylammonium. The trigonal group $\mathrm{NO}_{3}$ contains a central nitrogen atom and three peripheral oxygen atoms. Two types of vibration are distinguished in this atomic grouping, The vibrations describing the elongation modes along the axis of bands are called valence vibrations (Streching) noted $v_{\mathrm{s}}$ if they are symmetrical and $v_{\mathrm{as}}$ if they are asymmetrical and the deformation vibrations are generated by vibrations of the bond angles, following the movements of atomic groupings which are made almost perpendicular to the valence bond. The normal modes of vibration of the nitrate anion with ideal symmetry $D_{3 h}$ are shown diagrammatically in Fig. 12a. On the basis of the bibliographic data relating to the different types of bonds in organic molecules and on studies made on organic nitrates $[\mathbf{9 - 1 2}, \mathbf{1 9}, \mathbf{3 8}, \mathbf{3 9}]$ the different vibration bands existing in 3MBAN have been assigned in the infrared spectrum. The distribution of the different groups studied experimentally and theoretically is tabulated in Table 8 and graphically represented in the Fig. $12 b$.

- Vibrations of nitrate anion

The $\mathrm{NO}_{3}{ }^{-}$anion has 6 vibration modes by application of the relation $3 \mathrm{~N}-6$. These six vibration modes decompose according to a symmetrical elongation mode $\left(v_{1}, A_{1}^{\prime}\right.$, Raman), a mode of out-of-plane deformation $\left(v_{2}, A_{2}^{\prime \prime}, I R\right)$, a doubly degenerate mode of asymmetric elongation $\left(v_{3}, E ', I R\right.$ and Raman) and a doubly degenerate mode of deformation in the plane $\left(v_{4}, E^{\prime}\right.$, IR and Raman). The various proposals for assignments of symmetrical and asymmetrical vibration frequencies of the $\mathrm{NO}_{3}{ }^{-}$grouping are located in the spectral region $1700-1070 \mathrm{~cm}^{-1}$, while deformation vibration in the plane and out of plane are observed between $1070-640 \mathrm{~cm}^{-}$ 
1 . Here, the stretching vibrations $v_{\mathrm{as}}\left(\mathrm{NO}_{3}{ }^{-}\right)$are observed around 1380 and $1305 \mathrm{~cm}^{-1}$ in the experimental IR spectrum. The same stretching vibrations are predicted at 1726 and $1535 \mathrm{~cm}^{-1}$ by the DFT method. Other stretching vibrations $v_{\mathrm{s}}\left(\mathrm{NO}_{3}{ }^{-}\right)$were observed experimentally and theoretically at 1044 and $959 \mathrm{~cm}^{-1}$, respectively. The band which is located experimentally towards $827 \mathrm{~cm}^{-1}$ is related to the outside plane deformation mode of $\mathrm{NO}_{3}{ }^{-}$group; this mode is theoretically calculated at $794 \mathrm{~cm}^{-1}$. Finally the mode $v_{4}\left(\mathrm{NO}_{3}{ }^{-}\right)$appears in the spectral range between 752 and $530 \mathrm{~cm}^{-1}$. These values are in good agreement with those calculated at 695 and $614 \mathrm{~cm}^{-1}$.

- Ring vibration of 3MBA

The located band at $3050 \mathrm{~cm}^{-1}$ is due to the $\mathrm{C}_{\text {aryl }}-\mathrm{H}$ stretching vibration, the latter is predicted by DFT at 3078 and $3068 \mathrm{~cm}^{-1}$. The bands between 1650 and $1480 \mathrm{~cm}^{-1}$ are attributed to the $\mathrm{C}=\mathrm{C}$ stretching vibration of the aromatic ring. These vibrations have no particular features compared to those calculated (1650, 1642 and $1628 \mathrm{~cm}^{-1}$ ). By focusing on the bending vibrations in the plane and out-of-plane $\mathrm{C}_{\text {aryl }}-\mathrm{H}$, the frequencies of these vibrations appear as strong to strong medium bands experimentally in the spectral range $1553-1007 \mathrm{~cm}^{-1}$. In the theoretical FT IR spectrum, these vibrations are limited between 1628 and $1064 \mathrm{~cm}^{-1}$. Finally, the spectral range between 1000 and $470 \mathrm{~cm}^{-1}$ is assigned to the in-plane and out-of-plane vibration modes of $\mathrm{C}-\mathrm{C}$ and $\mathrm{C}=\mathrm{C}$ groups. These vibrations are calculated in the frequency region between 1016 and $400 \mathrm{~cm}^{-1}$.

- Vibration modes of $\mathrm{R}-\mathrm{NH}_{3}{ }^{+}$groups.

The 3-methylbenzylamine belongs to the class of primary amines. The two valence vibrations $v\left(-\mathrm{NH}_{3}{ }^{+}\right)$symmetrical and asymmetric are manifested in a single broad band and being in the $3500-3000 \mathrm{~cm}^{-1}$. This is already confirmed experimentally and theoretically where the bands correspond to asymmetrical stretching vibrations $-\mathrm{NH}_{3}{ }^{+}$located respectively around $3416 \mathrm{~cm}^{-}$ ${ }^{1}$ (experiment) and $3549 \mathrm{~cm}^{-1}$ (DFT). Meanwhile, the other symmetric vibration appears experimentally at $3218 \mathrm{~cm}^{-1}$ and theoretically at $3471 \mathrm{~cm}^{-1}$. On the other hand, the deformation vibration bands occur experimentally in the region $1600-1575 \mathrm{~cm}^{-1}$ for $\delta_{\text {as }}$ $\left(-\mathrm{NH}_{3}{ }^{+}\right)$and around $1516 \mathrm{~cm}^{-1}$ for $\delta_{\mathrm{s}}\left(-\mathrm{NH}_{3}{ }^{+}\right)$. These bands provided by the DFT method around 1726 and $1535 \mathrm{~cm}^{-1}$ respectively. The $v_{\mathrm{N}-\mathrm{C}}$ and $v_{\mathrm{C}-\mathrm{C}}$ valence vibration bands lie in the $1230-1020 \mathrm{~cm}^{-1}$ region. These vibrations are calculated by DFT in the spectral range 1200$1003 \mathrm{~cm}^{-1}$. Weak N-H...O bonds appear in the vibration spectrum in the form of disturbed vibrations of the $-\mathrm{NH}_{3}{ }^{+}$group of the protonated cation 3-methylbenzylammonium. The wide 
band estimated at $2341 \mathrm{~cm}^{-1}$ in the calculated IR spectrum is attributed to the $\mathrm{N}-\mathrm{H}$... stretching vibration.

- Vibration modes of $-\mathrm{CH}_{2}$ group

The valence vibration of $-\mathrm{CH}_{2}$ takes place around $3000 \mathrm{~cm}^{-1}$, however the deformation vibration of this group is expected around $1400 \mathrm{~cm}^{-1}$. Indeed experimentally the bands observed at 3050 and $3000 \mathrm{~cm}^{-1}$ in the infrared spectrum are relative respectively at the symmetrical and asymmetrical stretching of the methylene group $\left(-\mathrm{CH}_{2}\right)$. These frequencies are in good agreement with those predicted theoretically $\left(3024 \mathrm{~cm}^{-1}\right)$. The deformation vibration bands are located experimentally around $1600 \mathrm{~cm}^{-1}$ and theoretically around 1650 $\mathrm{cm}^{-1}$. In conclusion, these vibrations are modified by the presence of electronegative groups (Oxygen) making it possible to establish $\mathrm{C}-\mathrm{H}$... O hydrogen bonds.

- Vibrations of $-\mathrm{CH}_{3}$ group

The methyl group vibrations are similar to those of the vibrations of $-\mathrm{NH}_{3}{ }^{+}$group. Therefore the weak band observed at $3217 \mathrm{~cm}^{-1}$ in the IR spectrum is associated with the asymmetric stretching vibration $-\mathrm{CH}_{3}$. The same vibration is dictated at $3182 \mathrm{~cm}^{-1}$ by DFT level. The symmetrical stretching mode of the methyl group is detected experimentally and theoretically at $3068 / 3160 \mathrm{~cm}^{-1}$ in the IR spectrum. Concerning the shear, bending in the plane and tilting $-\mathrm{CH}_{3}$ vibrations, these vibrations are localized in the experimental spectral range varying from $1610-1044 \mathrm{~cm}^{-1}$ which is well correlated at the DFT level.

\subsection{UV-Vis absorption}

The UV-Visible spectrum of 3MBAN film compound (Fig.13) was recorded using a "PERKIN Lambda 19" room temperature spectrophotometer using quartz curettes with $1 \mathrm{~cm}$ optical path. This technique consists of adding to the tank a solution of the sample in $2 \mathrm{~mL}$ of ethanol with a concentration of $2.10^{-3} \mathrm{~mol} \cdot \mathrm{L}^{-1}$. The spectrum has two absorption bands, the first band which is the most intense, located around $274 \mathrm{~nm}$, corresponds to a $\pi \rightarrow \pi^{*}$ transition relating to the phenyl grouping of 3-methylbenzylammonium organic cation. The second band, which is very wide and not very intense, has a maximum in the vicinity of $305 \mathrm{~nm}$ attributable to the $n \rightarrow \pi^{*}$ transition of the nitrate group [9]. Ultraviolet spectrum analysis of $3 \mathrm{MBAN}$ has been investigated in ethanol solvent by theoretical calculation (DFT) at the 6$311++\mathrm{G}(\mathrm{d}, \mathrm{p})$ level of theory and is within $200-800 \mathrm{~nm}$ range. The shift between calculated and measured transitions is commonly observed in DFT calculations employing the B3LYP functional. Therefore, $3 \mathrm{MBAN}$ is a wide band gap of dielectric material. This value ( $\mathrm{Eg}=$ $5.34 \mathrm{eV}$ ) suggests that this compound could be used for optical applications in the far UV region [57]. 


\section{Conclusions}

In this study, according to a very precise experimental protocol, a new non-centrosymmetric hybrid material consisting of a nitrate group as a mineral anion and a monoprotonated nitrogen base (3-methylbenzylammonium) as an organic matrix is synthesized. The discussion of the crystal structure of this new crystal by X-ray diffraction shows that 3MBAN crystallizes in the monoclinic crystal system $(\mathrm{Cc})$ and is dominated by classical hydrogen bonds $\mathrm{N}-\mathrm{H} . . . \mathrm{O}$ and $\mathrm{C}-\mathrm{H} . . . \mathrm{O}$ forming a layered structure. The structural and spectroscopic (IR) models were also presented by the DFT method using the $6-31++G(d, p)$ base and compared with the experimental data which show good agreement. The vibrational wavenumbers of the fundamental modes of 3MBAN have been precisely assigned and analyzed. The strong bands between 1380 and 1305 and cm$~^{-1}$ are attributed to the asymmetric stretching mode of the $\mathrm{NO}_{3}$ group and the set of bands in the $3343-2840 \mathrm{~cm}^{-1}$ domain of frequency, assigned to the stretching modes N-H... . The HS analysis shows that the 3MBAN structure is stabilized by $\mathrm{H} \ldots \mathrm{H}, \mathrm{H} \ldots \mathrm{O}, \mathrm{C} \ldots \mathrm{H}, \mathrm{N} \ldots \mathrm{O}, \mathrm{O} \ldots \mathrm{O}, \mathrm{C} \ldots \mathrm{O}$ and $\mathrm{H} \ldots \mathrm{N}$ contacts, where the H...H, O...H / H...O participate almost $3 / 4$ of the entire Hirshfeld surface (77.7\%). The AIM, RDG, ELF analyzes were used to study the non-covalent interactions more precisely, the network of N-H... O hydrogen bonds, they reveal the high stability of the monomeric structure compared to the demiric one. The border orbitals show that our new material has high kinetic stability, low chemical reactivity $(\Delta \mathrm{E}=5.34 \mathrm{eV})$ and high biological activation $(\mu<0)$. The nonlinear optical properties of the studied molecule were calculated via polarizability and hyperpolarizability in the first order, we also envisage carried out a comparative study with the measurements NLO of urea. These measurements allowed the conclusion that $3 \mathrm{MBAN}$ is a good candidate for NLO equipment. The TG-DTA analysis shows that the 3 MBAN crystals are stable up to $389 \mathrm{~K}$, very close to the melting point (395 $\mathrm{K}$ ) in order to undergo total decomposition around $495 \mathrm{~K}$. The optical properties were investigated by optical absorption.

\section{Acknowledgements}

This work was supported by the Ministry of Higher Education and Scientific Research of Tunisia. 


\section{REFERENCES}

[1] C. Sanchez, F. Ribot, Design of hybrid organic-inorganic materials synthesized via sol-gel chemistry, New J. Chem. 18 (1994) 1007-1047.

[2] J. Wen, G. L. Wilkes, Chem. Mater. 8 (1996) 1667-1681.

[3] P. Englebienne, A.V. Hoonacker, Goldeconductive polymer nanoparticles: a hybrid material with enhanced photonic reactivity to environmental stimuli, J. Colloid Interface Sci. 292 (2) (2005) 445-454.

[4] Y. Li, Y. Yu, L. Wu, J. Zhi, Processable polyaniline/titania nanocomposites with good photocatalytic and conductivity properties prepared via peroxotitanium complex catalyzed emulsion polymerization approach, Appl. Surf. Sci. 273 (2013) 135-143.

[5] L.M. Novena, S.S. Kumar, S. Athimoolam, Improved solubility and bioactivity oftheophylline (a bronchodilator drug) through its new nitrate salt analysed by experimental and theoretical approaches, J. Mol. Struct. 1116 (2016) 45-55.

[6] J. Zyss, D. S. Chemla, Nonlinear Optical Properties of Organic Molecules and Crystals. Academic Press: Orlando, FL, 1987.

[7] H. S. Nalwa, S. Miyata, Nonlinear Optics of Organic Molecules and Polymers. CRC Press: Boca Raton, FL, 1996.

[8] M. C. Daniel, D. Astruc, Gold nanoparticles: assembly, supramolecular chemistry, quantum-size-related properties, and applications toward biology, catalysis, and nanotechnology, Chem. Rev. 104 (2004) 293-346.

[9] S. Gatfaoui, A. Mezni, T. Roisnel, H. Marouani, Synthesis, characterization, Hirshfeld surface analysis and antioxidant activity of a novel organic-inorganic hybrid material 1-methylpiperazine-1,4-diium bis(nitrate), J. Mol. Struct. 1139 (2017) 52-59.

[10] S. Gatfaoui, N. Issaoui, A. Mezni, F. Bardak, T. Roisnel, A. Atac, H. Marouani, Synthesis, structural and spectroscopic features, and investigation of bioactive nature of a novel organic-inorganic hybrid material 1H-1,2,4-triazole-4-ium trioxonitrate, J. Mol. Struct. 1150 (2017) 242-257.

[11] S. Gatfaoui, A. Sagaama, N. Issaoui, T. Roisnel, H. Marouani, Synthesis, experimental, theoretical study and molecular docking of 1-ethylpiperazine-1,4-diium bis(nitrate), Solid State Sci. 106 (2020) 106326

[12] L. M. Novena, S. S. Kumar, S. Athimoolam, Improved solubility and bioactivity of Theophylline (a Bronchodilator drug) through its new nitrate salt analysed by experimental and theoretical approaches, J. Mol. Struc. 1116 (2016) 45-55. 
[13] M.G. Bogaert, Clinical pharmacokinetics of nitrates, Cardiovasc Drugs Ther. 8 (5) (1994) 693-699.

[14] S.A. Brandán (Ed.), Nitrate: Occurrence, Characteristics and Health Considerations, Nova Science Publishers, Inc, 2012, ISBN 978-1-62257-352-3. Edited Collection.

[15] S.A. Brandán, in: Ken Derham (Ed.), A Structural and Vibrational Study of the Chromyl Chlorosulfate, Fluorosulfate, and Nitrate Compounds, vol. 1, Springer Science, Business Media B.V., Van Godewijckstraat 30, 3311 GZ Dordrecht, Netherlands, 2012, ISBN 978-94-007-5762-2.

[16] S.A. Brandán (Ed.), Descriptors, Structural and Spectroscopic Properties of Heterocyclic Derivatives of Importance for the Health and the Enviromental, Nova Science Publishers, Inc, 2015, ISBN 978-1-63482-708-9. Edited Collection.

[17] M.V. Castillo, E. Romano, H.E. Lanús, S.B. Díaz, A. Ben Altabef, S.A. Brandán, Theoretical structural and experimental vibrational study of niobyl nitrate, J. Mol. Struct. 994 (2011) 202-208.

[18] K.E. Torfgård, J. Ahlner, Mechanisms of action of nitrates, Cardiovasc Drugs Ther. 8 (5) (1994) 701-717.

[19] J. Baran, M. Drozd, H. Ratajczak, A. Pietraszko, Bis(glycine) lithium nitrate - A new non-centrosymmetric crystal: X-ray structure, vibrational spectra and DSC investigations, J. Mol. Struct. 927 (2009) 43-53.

[20] Bruker, APEX2, SAINT and SADABS, Bruker AXS Inc, Madison,Wisconsin, USA, 2006.

[21] A. Altomare, M.C. Burla, M. Camalli, G.L. Cascarano, C. Giacovazzo, A. Guagliardi, A. G .G. Moliterni, G. Polidori, R. Spagna, J. Appl. Cryst. 32 (1999) 115.

[22] G. M. Sheldrick, Crystal structure refinement with SHELXL, Acta Cryst. C71 (2015) 3-8.

[23] L. J. Farrugia, WinGX and ORTEP for windows: an update, J. Appl. Cryst. 45 (2012) 849-854.

[24] K. Brandenburg, Diamond Version 2.0 Impact. (GbR, Bonn, 1998).

[25] S. K. Wolff, D. J. Grimwood, J. J. McKinnon, D. Jayatilaka, M. A. Spackamn, Crystal Explorer 3.1, University of Westren Australia, Perth, 2013.

[26] M. J. Frisch, et al., GAUSSIAN 09, Revision A.02, Gaussian, Inc., Wallingford, CT, 2009.

[27] R.I. Dennington, T. Keith, J. Millam, GaussView, Version 5.0.8, Semichem. Inc, Shawnee Mission, KS, 2008. 
[28] T. Lu, F. Chen, Multiwfn: a multifunctional wavefunction analyzer, J. Comput. Chem. 33 (2012) 580-592.

[29] P. S. V. Kumar, V Raghavendra, V. Subramanian, Bader's Theory of Atoms in Molecules (AIM) and its Applications to Chemical Bonding, J. Chem. Sci. 128, (2016) 1527-1536.

[30] W. Humphrey, A. Dalke, K. Schulten, VMD-visual molecular dynamics, J. Mol. Graph. 14 (1996) 33-38.

[31] M.H. Jamróz, Vibrational Energy Distribution Analysis, vol. 4, Computer Program, Poland, 2004. VEDA.

[32] S. Gatfaoui, H. Marouani, M. Rzaigui, 4-Methylbenzylammonium nitrate, Acta Cryst. E69 (2013) 01453.

[33] S. Gatfaoui, H. Marouani, M. Rzaigui, 1,1,4,7,7-Pentamethyldiethylenetriammonium trinitrate, Acta Cryst. E70 (2014) o198.

[34] S. Gatfaoui, H. Dhaouadi, T. Roisnel, M. Rzaigui, H. Marouani, mXylylenediaminium dinitrate, Acta Cryst. E70 (2014) o398-o399.

[35] S. Gatfaoui, H. Marouani, T. Roisnel, H. Dhaouadi, Dopaminium nitrate, Acta Cryst. E70 (2014) o571-0572.

[36] S. Gatfaoui, T. Roisnel, H. Dhaouadi, H. Marouani, trans-2,5- dimethylpiperazine-1,4diium dinitrate, Acta Cryst. E70 (2014) 0725.

[37] R. Aarthi, A. Thiruvalluvar, C. R. Raja, 4-Methylbenzylammonium chloride hemihydrate, IUCrData, 2 (2017) x171213.

[38] S. Gatfaoui, N. Issaoui, T. Roisnel, H. Marouani, A proton transfer compound template phenylethylamine: Synthesis, a collective experimental and theoretical investigations, J. Mol. Struct. 1191 (2019) 183-196.

[39] S. Gatfaoui, N. Issaoui, S. A. Brandán, T. Roisnel, H. Marouani, Synthesis and characterization of p-xylylenediaminium bis(nitrate). Effects of the coordination modes of nitrate groups on their structuraland vibrational properties, J. Mol. Struct. 1151 (2018) 152-168.

[40] M. Tahenti, S. Gatfaoui, N. Issaoui, T. Roisnel, A tetrachlorocobaltate(II) salt with 2amino-5-picolinium: Synthesis, theoretical and experimental characterization, J. Mol. Struct. 1207 (2020) 127781.

[41] C. Jelsch, K. Ejsmont, L. Huder, The enrichment ratio of atomic contacts in crystals, an indicator derived from the Hirshfeld surface analysis, IUCrJ 1 (2014) 119-128. 
[42] I. P. S. Kapoor, P. Srivastava, G. Singh, Preparation, characterization and thermolysis of phenylenediammonium dinitrate salts, J. Hazar. Mater. 150 (2008) 687-694.

[43] S. Cagnina, P. Rotureau, C. Adamo, Study of incompatibility of ammonium nitrate and its mechanism of decomposition by theoretical approach, Chem. Engine. Transac. 31 (2013) 823-828.

[44] U. Koch, P. L. A. Popelier, J. Phys. Chem. 99 (1995) 9747.

[45] I. Rozas, I. Alkorta, J. Elguero, Behavior of ylides containing N, O, and C atoms as hydrogen bond acceptors, J. Am. Chem. Soc. 122 (2000) 11154-11161.

[46] E. Espinosa, I. Alkorta, I. Rozas, J. Elguero, R. Molins, J. Chem. Phys. Lett., 336

[47] E.R. Johnson, S. Keinan, P. Mori-Sánchez, J. Contreras-García, A.J. Cohen, W. Yang, J. Am. Chem. Soc. 132 (2010) 6498-6506.

[48] C.R. Zhang, H.S. Chen, G.H.Wang, J. Chem. Res. Chin. U 20 (2004) 640.

[49] Y. Sun, X. Chen, L. Sun, X. Guo,W. Lu, J. Chem. Phys. Lett. 381 (2003) 397.

[50] O. Christiansen, J. Gauss, J. F. Stanton, J. Chem. Phys. Lett. 305 (1999) 147.

[51] P. Asokan, S. Kalainathan, Bulk crystal growth, optical, electrical, thermal, and third order NLO properties of 2-[4(diethylamino)benzylidene]malononitrile (DEBM) single crystal, J. Phys. Chem. C121 (40) (2017) 22384 -22395.

[52] C. Ben M'leh , S. A. Brandan , N. Issaoui, T. Roisnel, H. Marouani, Synthesis, molecular structure, vibrational and theoretical studies of a new non-centrosymmetric organic sulphate with promising NLO properties, J. Mol. Struct. 1171 (2018) 771-785.

[53] R.S. Mulliken, A new electro affinity scale; together with data on valence states and on valence ionization potentials and electron affinities, J. Chem. Phys. 2 (1934) 782794.

[54] R.G. Pearson, Chemical Hardness, John Wiley-VCH, Weinheim, 1997.

[55] R.G. Parr, L. von Szentpály, S. Liu, Electrophilicity index, J. Am. Chem. Soc. 121 (1999) 1922-1924.

[56] M. Salihovic, S. Huseinovic, S. Spirtovic-Halilovic, A. Osmanovic, A. Dedic, Z. Asimovic, D. Zavrsnik, DFT study and biological activity of some methylxanthines, Bull. Chem. Technol Bos Herzeg, 42 (2014) 31-36.

[57] B. K. Periasamy, R. S. Jebas, B. Thailampillai, Mat. Lett. 61 (2007) 1489. 


\section{List of Figures :}

Fig. 1. ORTEP drawing of $3 \mathrm{MBAN}$ with the atom-labeling scheme. Displacement ellipsoids are drawn at the $30 \%$ probability level. $\mathrm{H}$ atoms are represented as small spheres of arbitrary radii (a) and the optimized molecular structure (b).

Fig. 2. Projection along the $\vec{a}$ (a) and $\vec{c}$ axis (b) of atomic arrangement of 3MBAN.

Fig. 3. Hydrogen bond motifs in $3 \mathrm{MBAN}$ compound.

Fig. 4. $d_{\text {norm }}$ cartography (a), $d_{e}$ cartography (b) and fingerprint plot (c) of all contacts existing in 3MBAN molecule.

Fig. 5. Percentage of all contacts and atoms present in the $3 \mathrm{MBAN}$ material.

Fig. 6. DTA, TG curve of (3MBAN) at rising temperature.

Fig. 7. Monomer (a) and dimmer (b) AIM graphs of the studied compound mapped throughout Multiwfn program at B3LYP/6-311++G(d,p) level of theory.

Fig. 8. Reduced density gradient and isosurface density plot along with the color filled scale bar defining interaction limits for the Monomer (a) and dimmer (b) 3MBAN compound.

Fig. 9. Shaded surface map with projection effect of electron localization function (ELF) of Monomer (a) and dimmer (b) 3MBAN compound.

Fig. 10. The map for electron density in the XY plane of 3MBAN material.

Fig. 11. Frontier molecular orbital of $3 \mathrm{MBAN}$ crystal.

Fig. 12. vibrational movements in the $\mathrm{NO}_{3}{ }^{-}$ion (a) and theoretical and experimental FT-IR spectrum of 3MBAN compound (b).

Fig. 13. Experimental and theoretical UV/Vis spectra of 3MBAN compound. 
(a)

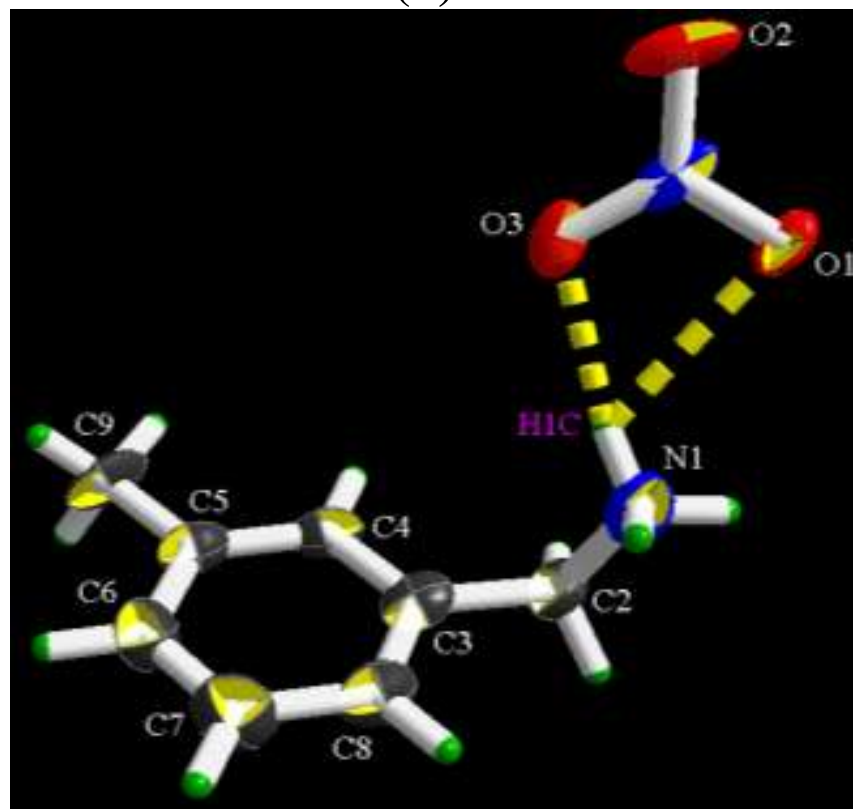

(b)

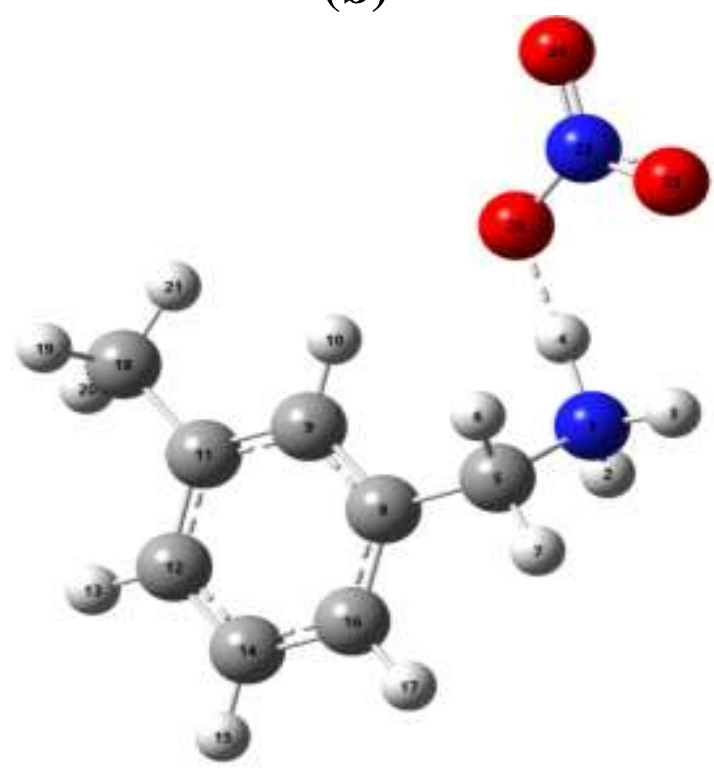

Fig.1

(a)

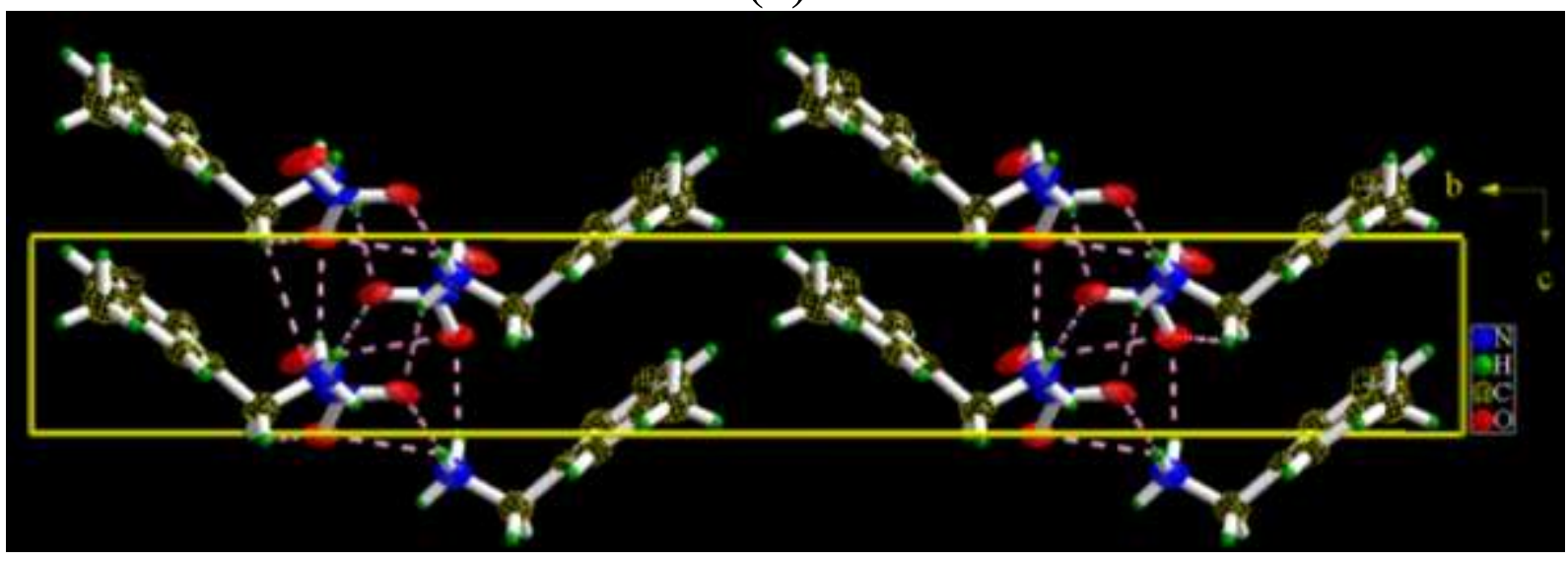

(b)

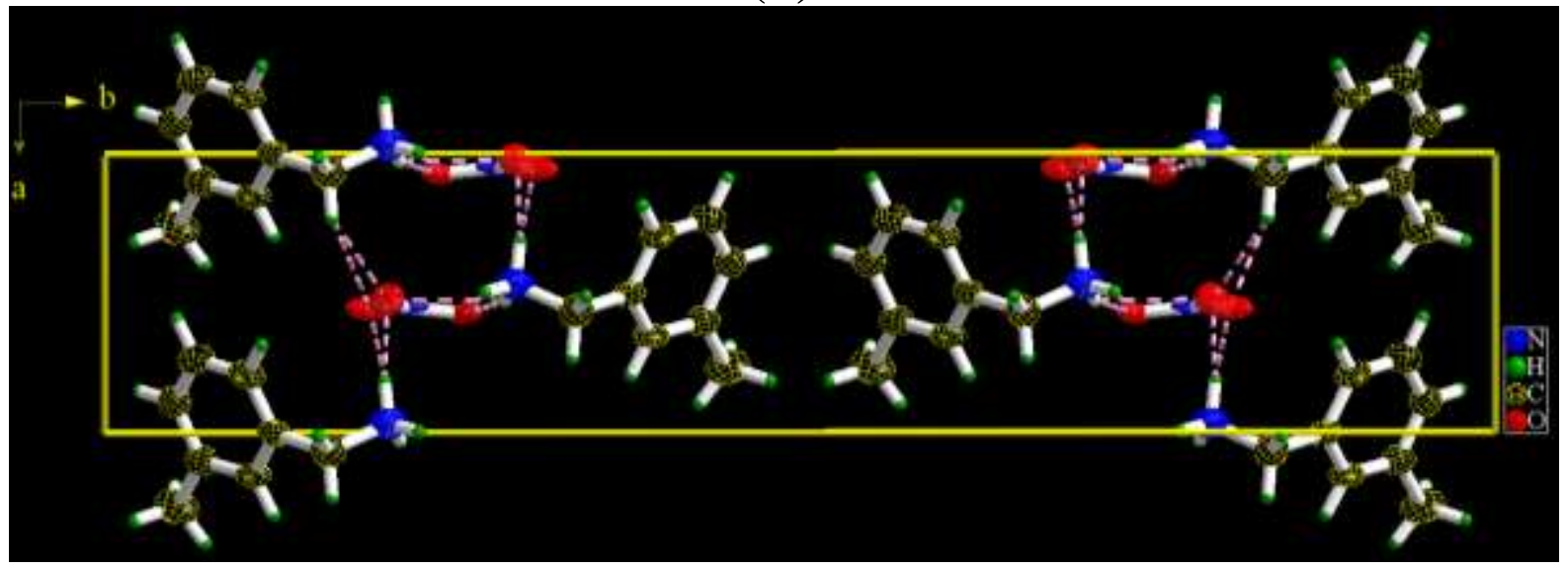

Fig.2 


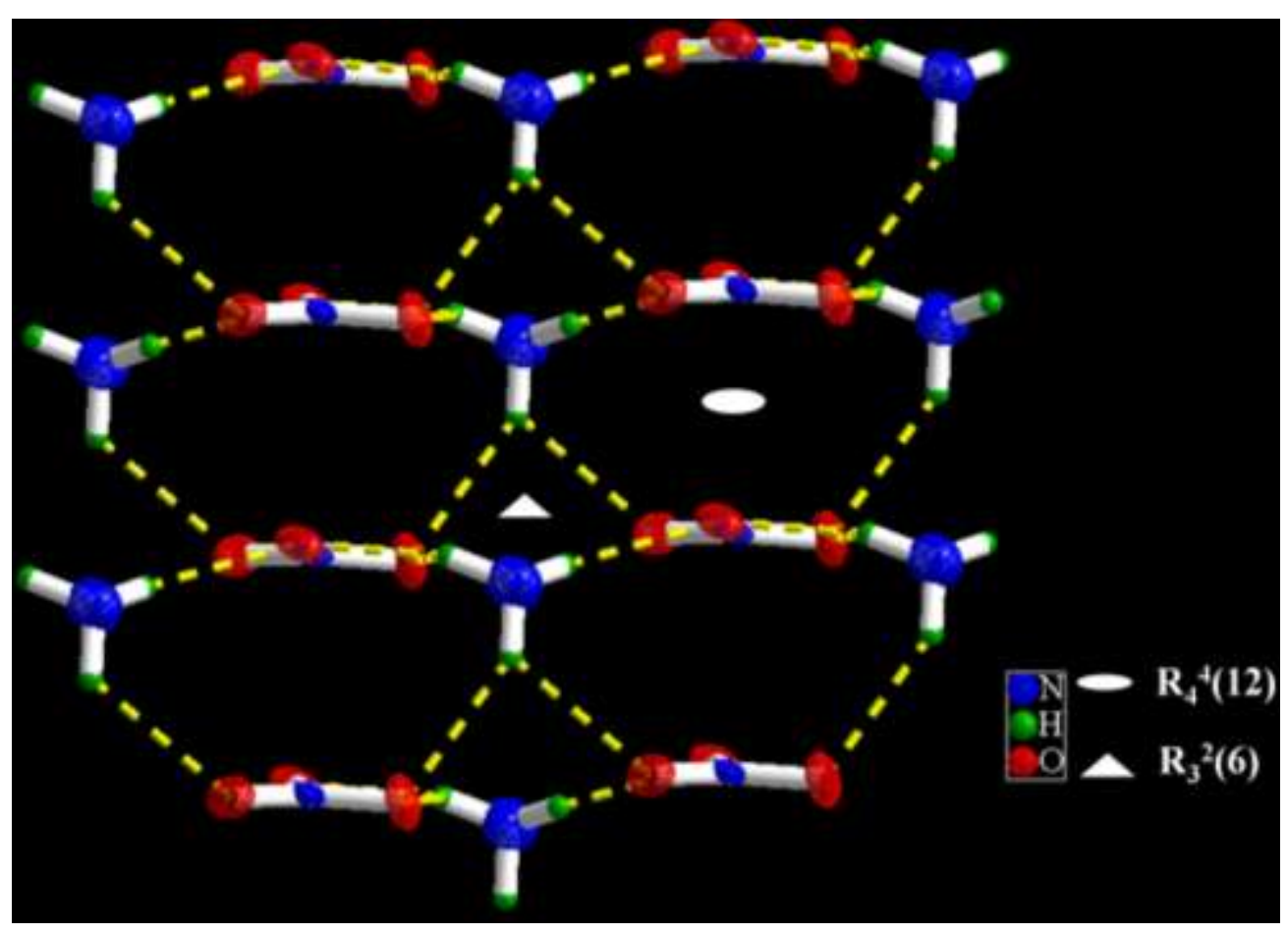

Fig.3

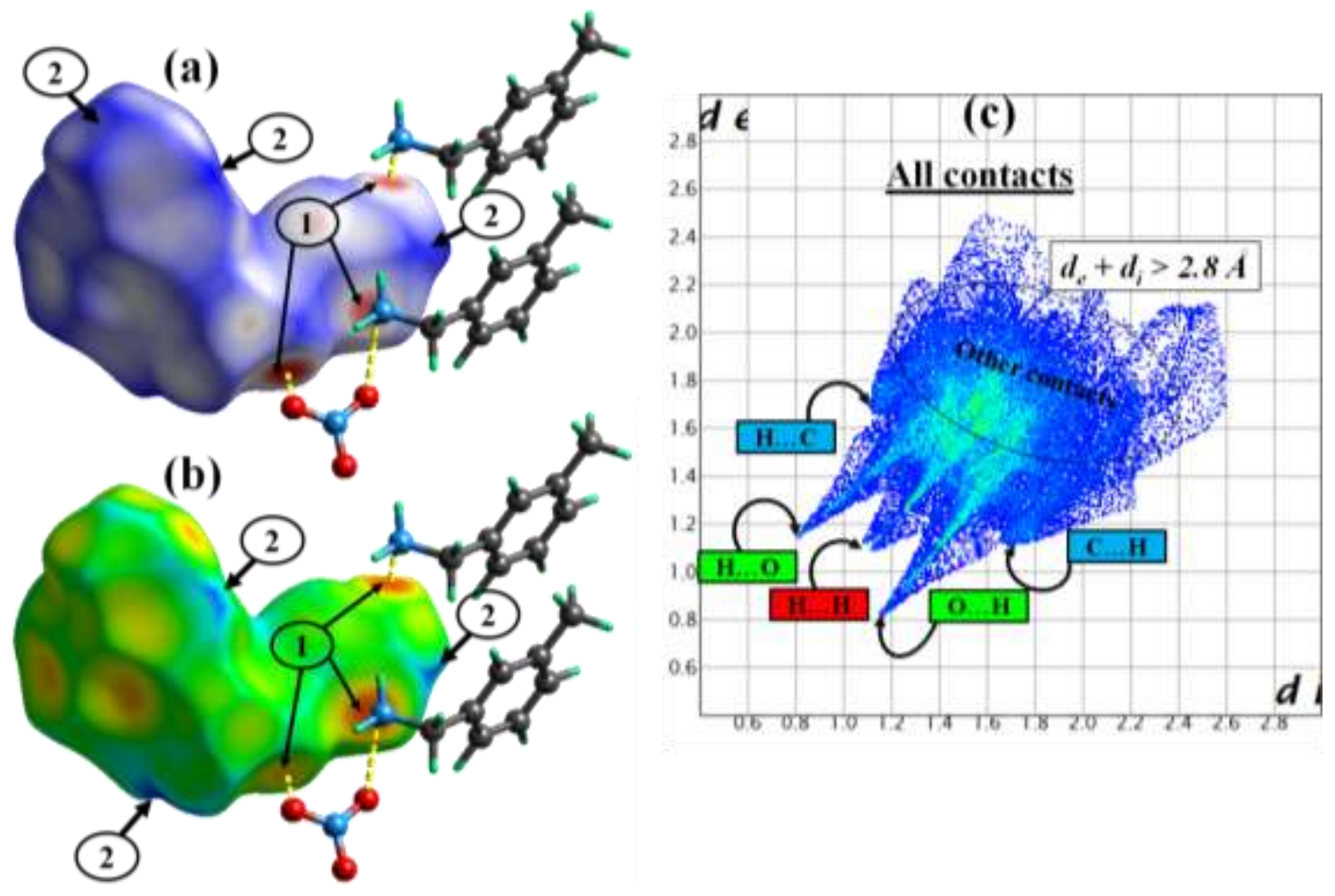

Fig.4 

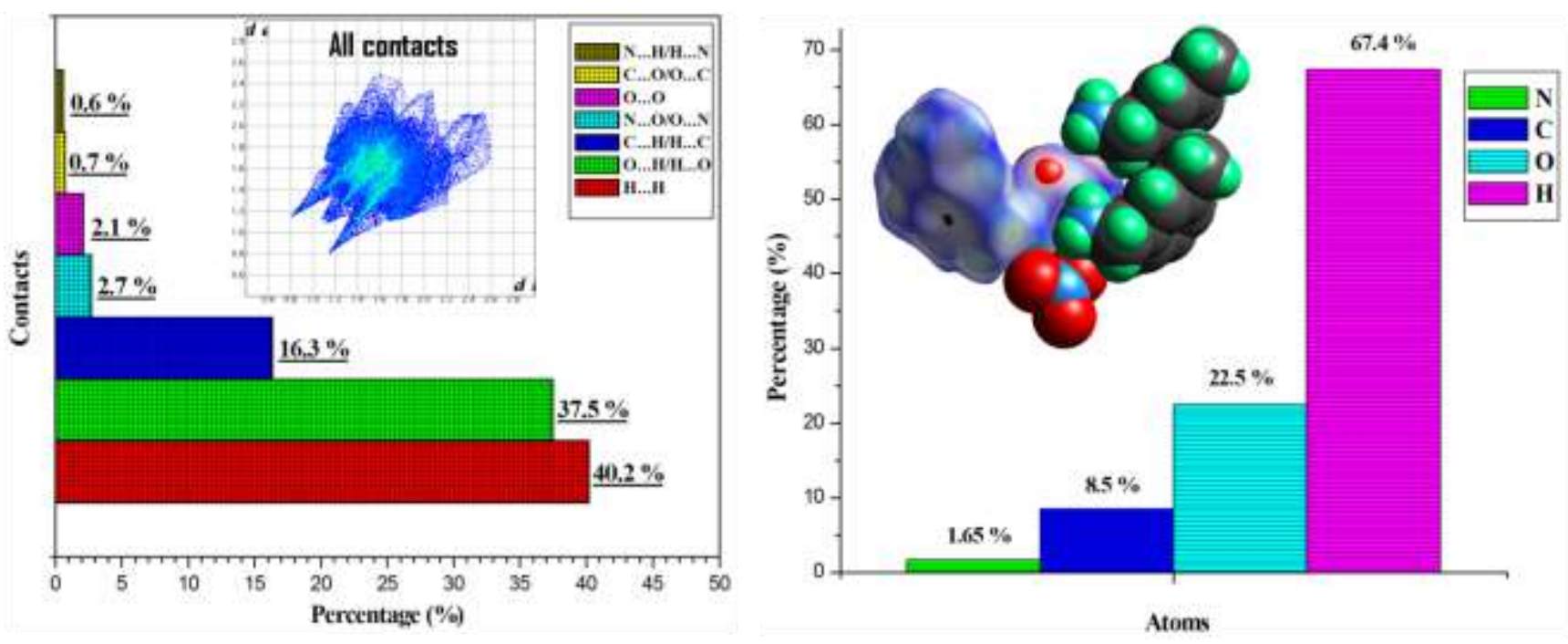

Fig.5

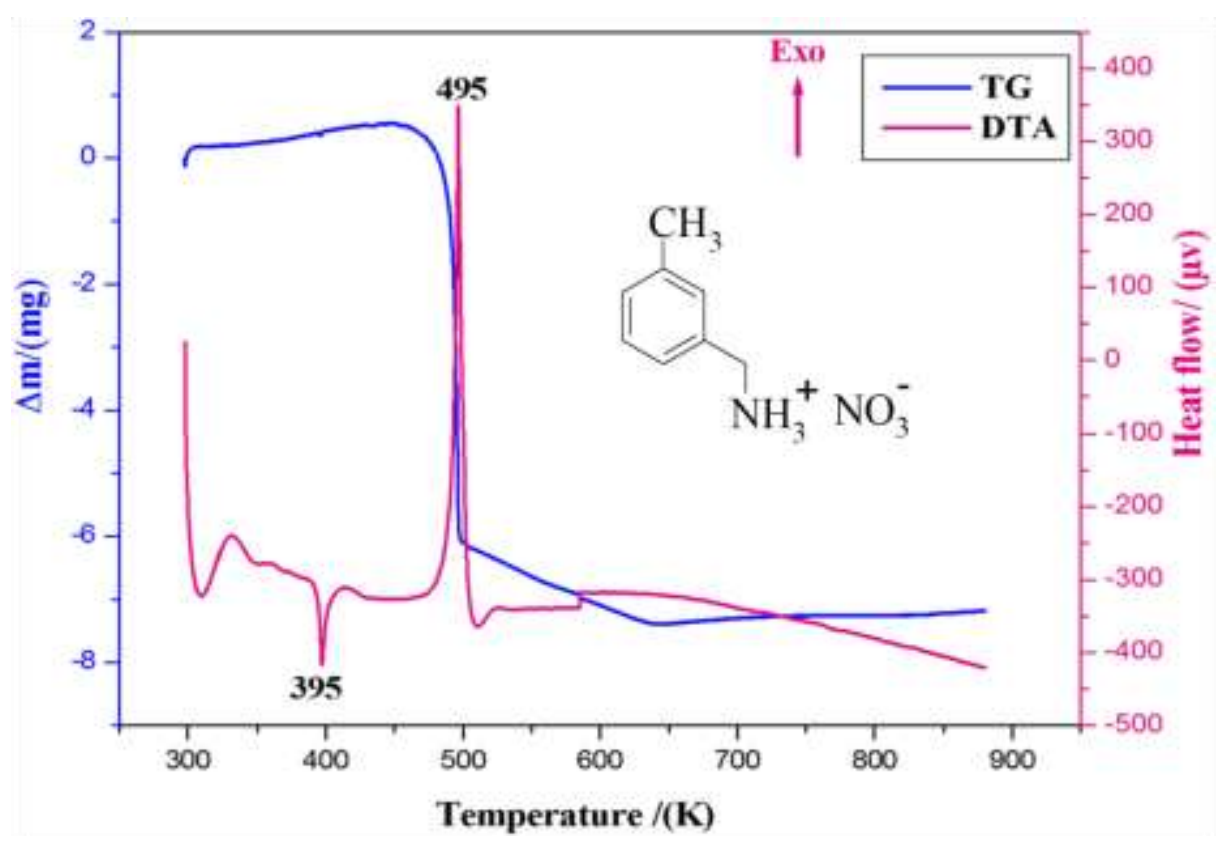

Fig.6 

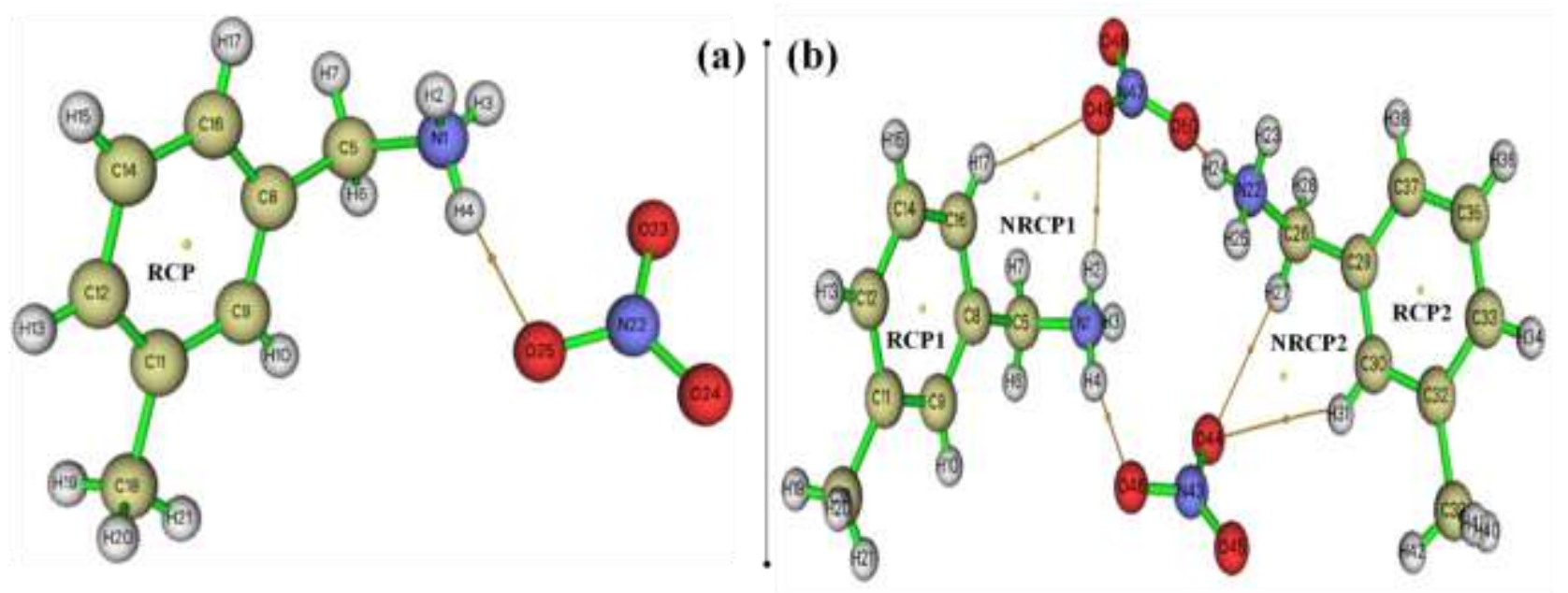

Fig.7
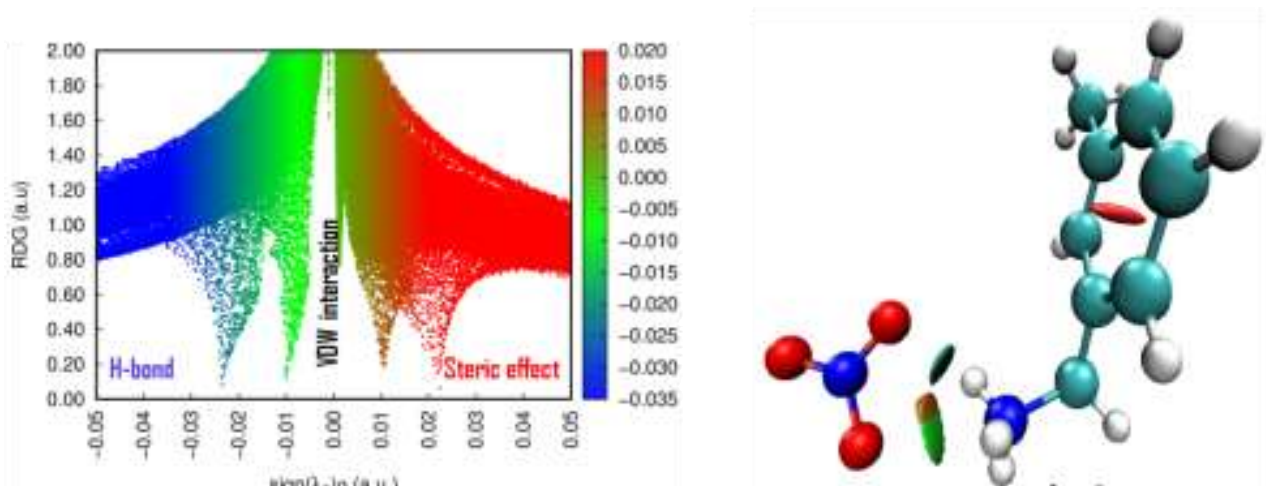

(a)
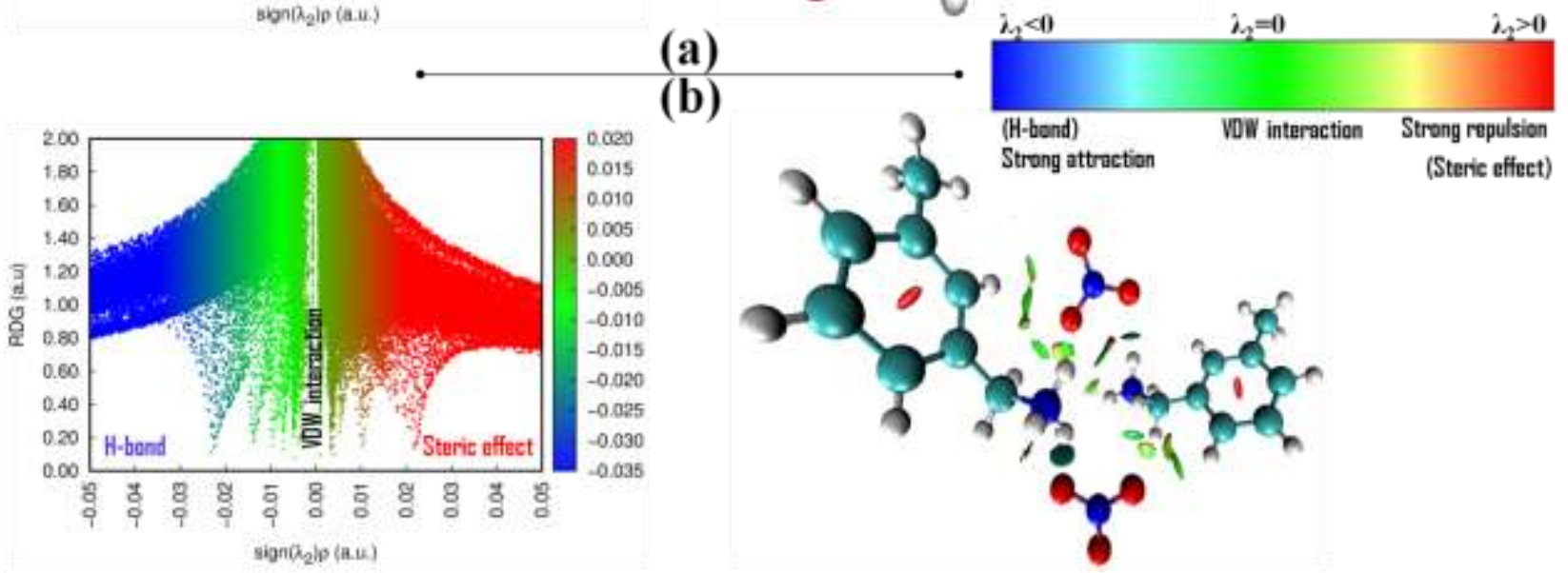

Fig.8 

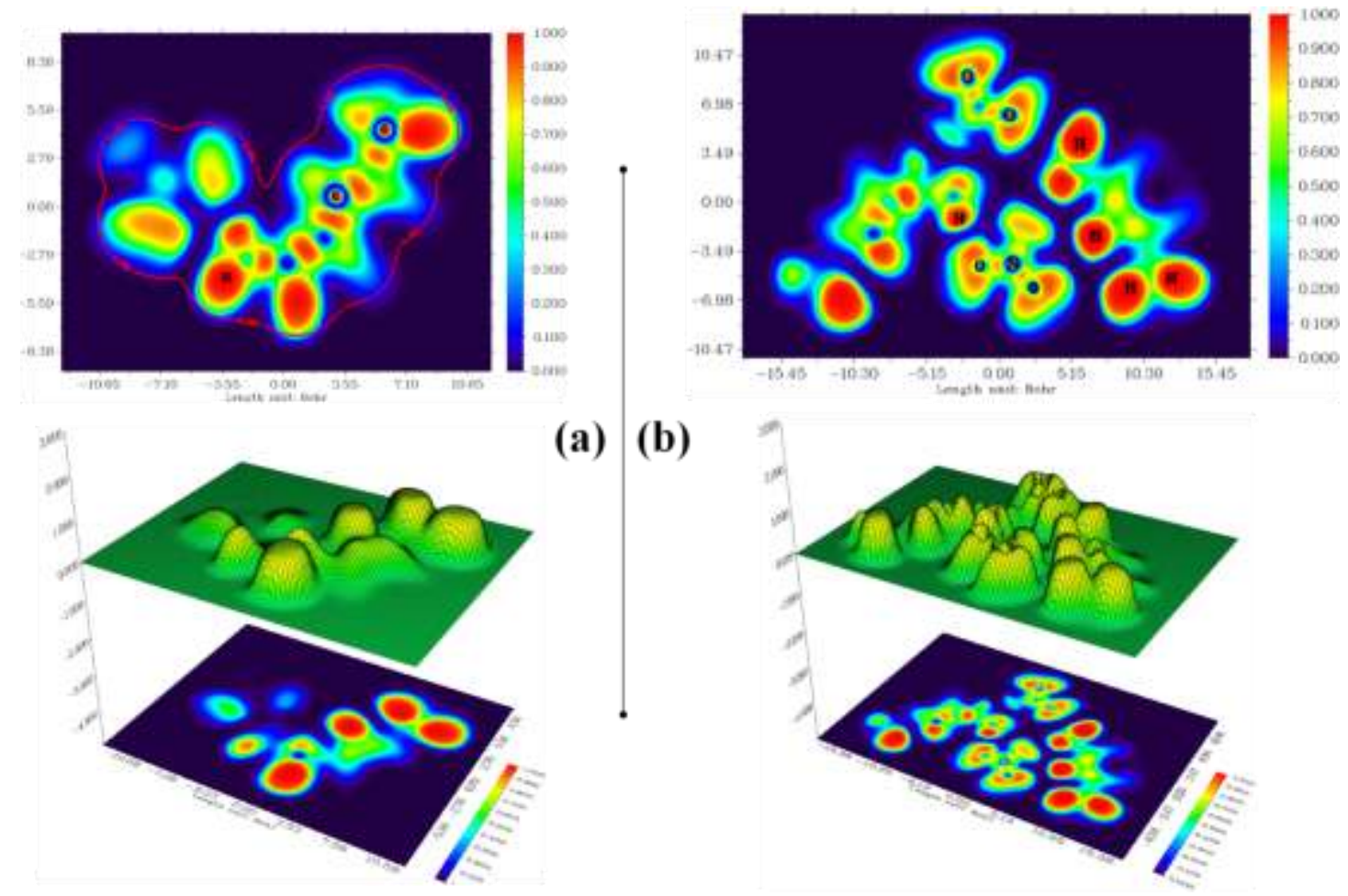

Fig.9 


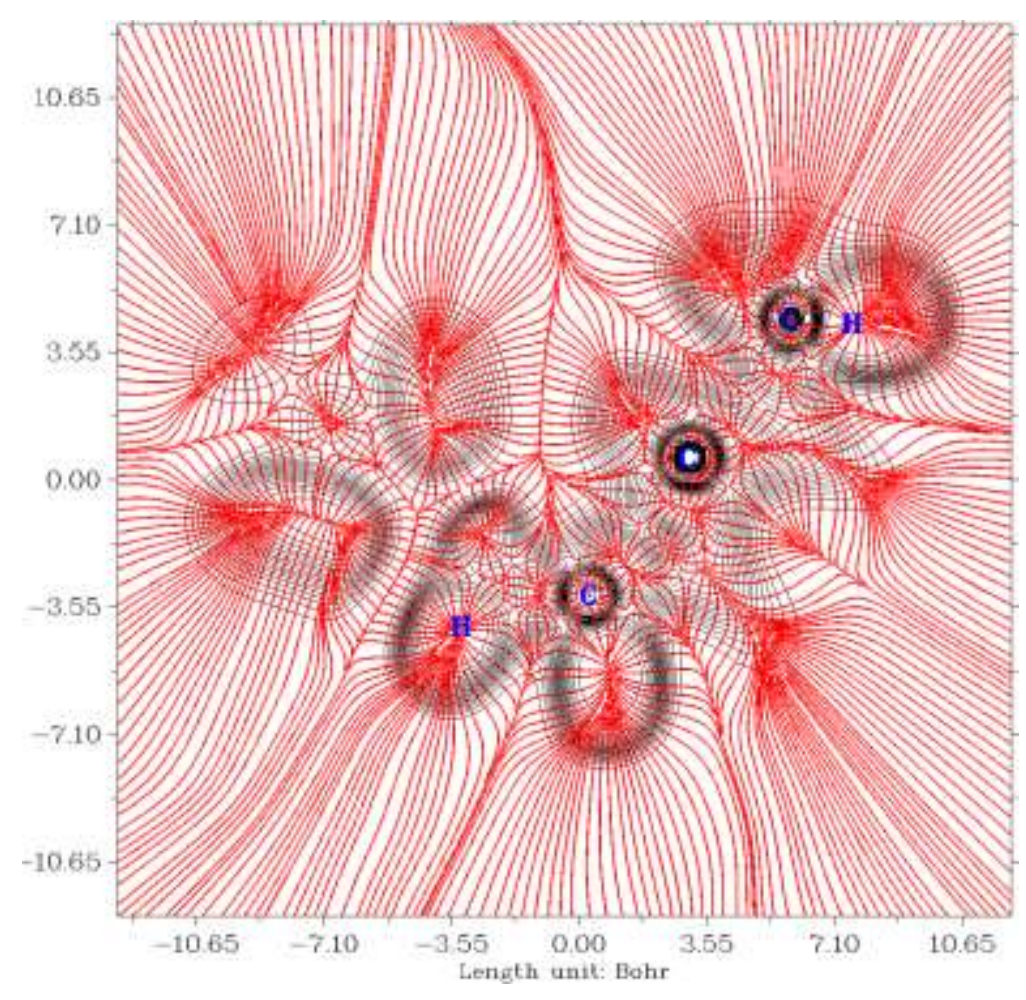

Fig.10

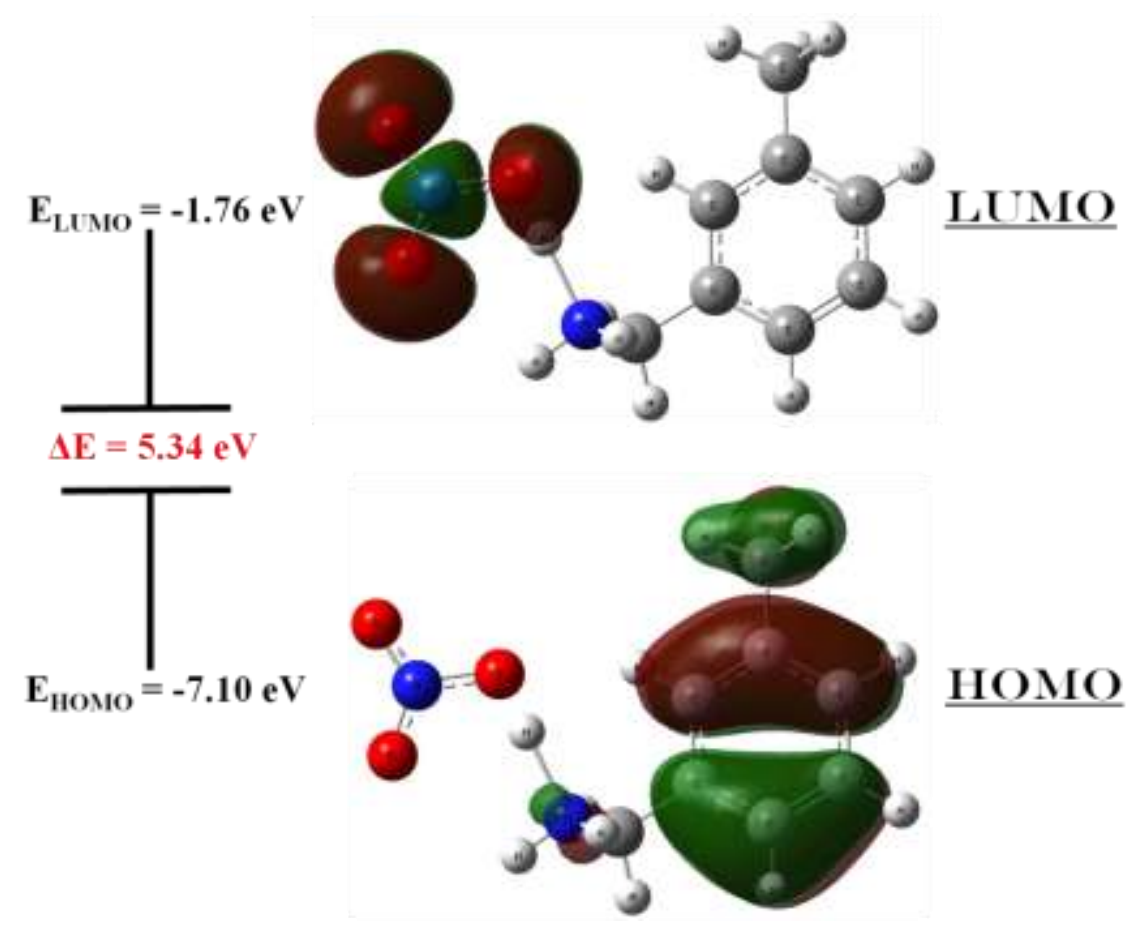

Fig.11 


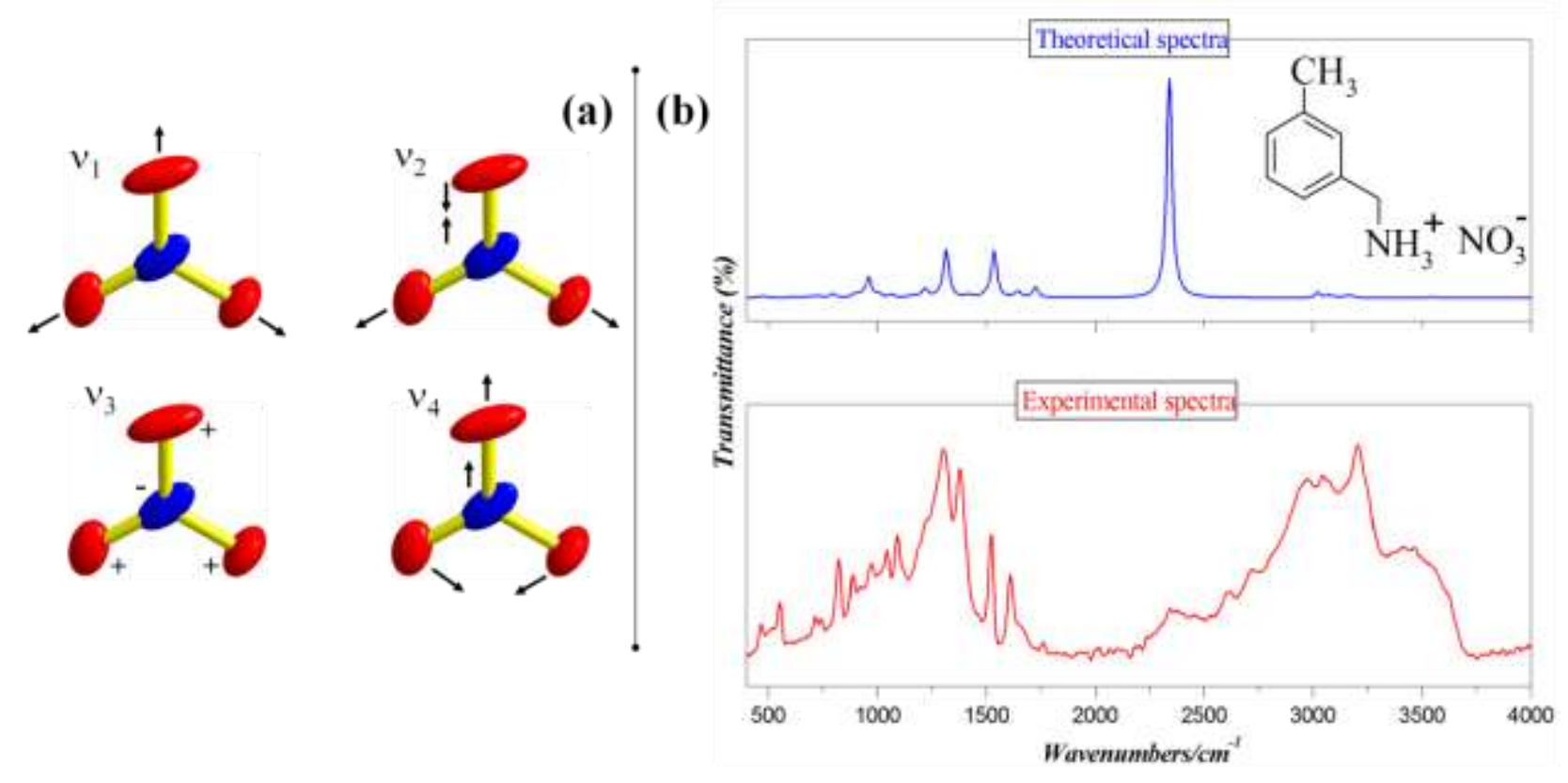

Fig.12

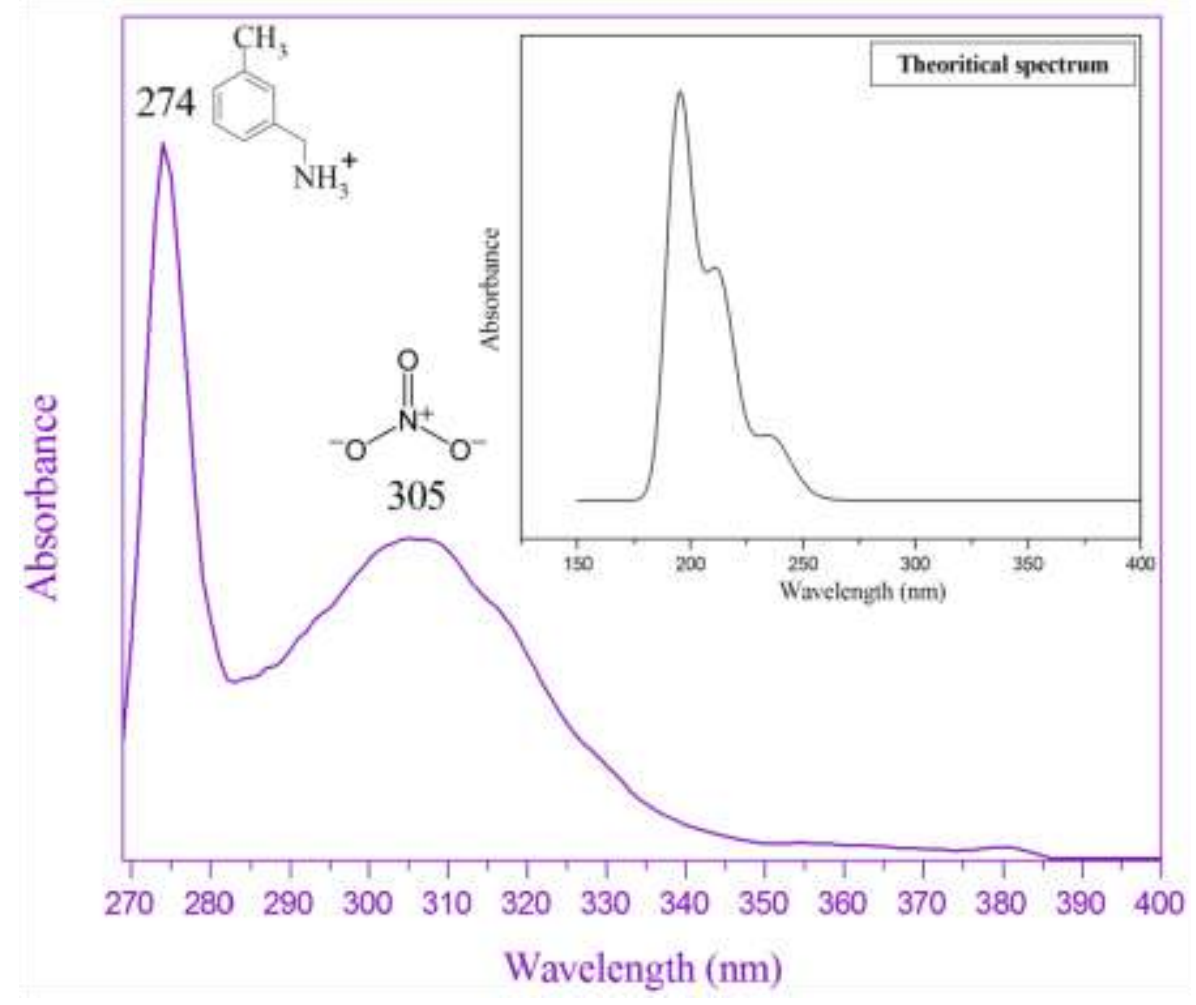

Fig.13 


\section{$\underline{\text { List of Tables }}$}

Table. 1 Crystal data and experimental parameters used for the intensity data collection strategy and final results of the structure determination.

Table. 2 Theoretical and experimental bond lengths $(\AA)$ and bond angles $\left(^{\circ}\right)$ of the title compound.

Table. 3 Hydrogen-bond geometry $\left(\AA{ }^{\circ}\right)$ of 3 MBAN.

Table. 4 Enrichment ratio of 3MBAN compound.

Table. 5 Topological parameters of monomer and dimer of 3MBAN compound calculated at DFT/B3LYP/6-311++G(d,p).

Table. 6 The electric dipole moment, polarizability, and first order hyperpolarizability values of the title compound.

Table. 7 Calculated energy value for the studied compound by using TD-B3LYP/6$311++\mathrm{G}(\mathrm{d}, \mathrm{p})$ method.

Table. 8 Observed and calculated wavenumbers $\left(\mathrm{cm}^{-1}\right)$ and assignments of 3MBAN molecule. 
Table 1

\begin{tabular}{ll}
\hline Empirical formula & $\mathrm{C}_{8} \mathrm{H}_{12} \mathrm{~N}\left(\mathrm{~N} \mathrm{O}_{3}\right)$ \\
Temperature & $150 \mathrm{~K}$ \\
Formula weight $\left(\mathrm{g} \mathrm{mol}^{-1}\right)$ & 184.20 \\
Crystal system & Monoclinic \\
Space group & $\mathrm{P} 2_{1} / \mathrm{c}$ \\
$\mathrm{a}, \mathrm{b}, \mathrm{c}(\mathrm{A})$ & $7.574(3), 29.494(10), 5.1894(15)$ \\
$\beta\left(^{\circ}\right)$ & $128.669(11)$ \\
$\mathrm{Z}$ & 4 \\
$\mathrm{~V}\left(\AA^{3}\right)$ & $905.1(5)$ \\
$\mathrm{F}(000)$ & 392 \\
Radiation type & $\mathrm{Mo} \mathrm{K \alpha}$ \\
$\mu\left(\mathrm{mm}^{-1}\right)$ & 0.104 \\
Crystal size $(\mathrm{mm})$ & $0.12 \mathrm{x} 0.49 \mathrm{x} 0.54$ \\
Index ranges & $-5 \leq \mathrm{h} \leq 9,-36 \leq \mathrm{k} \leq 24,-6 \leq 1 \leq 6$ \\
Reflections collected & 2217 \\
Independent reflections & 1281 \\
Reflections with I $>2 \sigma(\mathrm{I})$ & 1020 \\
$\mathrm{R}_{\text {int }}$ & 0.0406 \\
Diffractometer & $\mathrm{D} 8 \mathrm{VENTURE} \mathrm{Bruker} \mathrm{AXS}$ \\
Absorption correction & Multi-scan \\
$\mathrm{T}_{\text {min }}, \mathrm{T}_{\text {max }}$ & $0.980,0.989$ \\
Refined parameters & 120 \\
$\mathrm{R}\left[\mathrm{F}^{2}>2 \sigma\left(\mathrm{F}^{2}\right)\right]$ & 0.0571 \\
wR $\left(\mathrm{F}^{2}\right)$ & 0.1324 \\
Goodness of fit & \\
$\Delta \rho_{\text {max }}, \Delta \rho_{\text {min }}\left(\mathrm{e} \AA^{-3}\right)$ & \\
\hline
\end{tabular}


Table 2

\begin{tabular}{|c|c|c|c|c|c|}
\hline Parameters & $\begin{array}{c}\text { B3LYP/6- } \\
311++G(d, p)\end{array}$ & Exp & Parameters & $\begin{array}{c}\text { B3LYP/6- } \\
311++G(d, p)\end{array}$ & Exp \\
\hline N1-H2 & 1.01 & 0.91 & H3-N1-H4 & 103.47 & 109.5 \\
\hline N1-H3 & 1.02 & 0.91 & H3-N1-C5 & 111.79 & 109.5 \\
\hline N1-H4 & 1.13 & 0.91 & H4-N1-C5 & 110.21 & 109.5 \\
\hline N1-C5 & 1.50 & $1.47(5)$ & N1-C5-H6 & 105.66 & 109.3 \\
\hline $\mathrm{H} 4-\mathrm{O} 25$ & 1.47 & 1.47 & N1-C5-H7 & 108.64 & 109.3 \\
\hline C5-H6 & 1.09 & 0.99 & N1-C5-C8 & 111.16 & $111.8(3)$ \\
\hline $\mathrm{C} 5-\mathrm{H} 7$ & 1.09 & 0.99 & H6-C5-H7 & 108.48 & 107.9 \\
\hline $\mathrm{C} 5-\mathrm{C} 8$ & 1.50 & $1.50(6)$ & H6-C5-C8 & 111.86 & 109.3 \\
\hline C8-C9 & 1.40 & $1.38(6)$ & H7-C5-C8 & 110.81 & 109.3 \\
\hline $\mathrm{C} 8-\mathrm{C} 16$ & 1.39 & $1.39(6)$ & C5-C8-C9 & 120.3 & 121.1(4) \\
\hline C9-H10 & 1.08 & 0.95 & C5-C8-C16 & 120.06 & $119.5(4)$ \\
\hline C9-C11 & 1.39 & $1.39(6)$ & C9-C8-C16 & 119.62 & $119.4(4)$ \\
\hline $\mathrm{C} 11-\mathrm{C} 12$ & 1.40 & $1.38(6)$ & C8-C9-H10 & 119.59 & 119.4 \\
\hline C11-C18 & 1.50 & $1.50(6)$ & C8-C9-C11 & 121.08 & 121.3(4) \\
\hline $\mathrm{C} 12-\mathrm{H} 13$ & 1.08 & 0.95 & H10-C9-C11 & 119.31 & 119.4 \\
\hline $\mathrm{C} 12-\mathrm{C} 14$ & 1.39 & $1.38(7)$ & C9-C11-C12 & 118.36 & 118.2(4) \\
\hline C14-H15 & 1.08 & 0.95 & C9-C11-C18 & 120.68 & $121.6(4)$ \\
\hline C14-C16 & 1.39 & $1.37(7)$ & C12-C11-C18 & 120.93 & $120.2(4)$ \\
\hline C16-H17 & 1.08 & 0.95 & C11-C12-H13 & 119.42 & 119.4 \\
\hline C18-H19 & 1.09 & 0.98 & C11-C12-C14 & 121.01 & 121.2(4) \\
\hline $\mathrm{C} 18-\mathrm{H} 20$ & 1.09 & 0.98 & H13-C12-C14 & 119.56 & 119.4 \\
\hline $\mathrm{C} 18-\mathrm{H} 21$ & 1.09 & 0.98 & C12-C14-H15 & 120.00 & 120.0 \\
\hline $\mathrm{N} 22-\mathrm{O} 23$ & 1.24 & $1.25(5)$ & C12-C14-C16 & 120.09 & $120.0(5)$ \\
\hline $\mathrm{N} 22-\mathrm{O} 24$ & 1.21 & $1.23(5)$ & H15-C14-C16 & 119.89 & 120.0 \\
\hline $\mathrm{N} 22-\mathrm{O} 25$ & 1.31 & $1.25(5)$ & C8-C16-C14 & 119.81 & $120.0(5)$ \\
\hline $\mathrm{H} 2-\mathrm{N} 1-\mathrm{H} 3$ & 109.25 & 109.5 & C8-C16-H17 & 120.21 & 120.0 \\
\hline $\mathrm{H} 2-\mathrm{N} 1-\mathrm{H} 4$ & 110.28 & 109.5 & C14-C16-H17 & 119.97 & 120.0 \\
\hline H2-N1-C5 & 111.53 & 109.5 & C11-C18-H19 & 110.75 & 109.5 \\
\hline C11-C18-H20 & 111.28 & 109.5 & H20-C18-H21 & 108.35 & 109.5 \\
\hline C11-C18-H21 & 111.34 & 109.5 & $\mathrm{O} 23-\mathrm{N} 22-\mathrm{O} 24$ & 124.21 & $120.4(4)$ \\
\hline H19-C18-H20 & 107.34 & 109.5 & $\mathrm{O} 23-\mathrm{N} 22-\mathrm{O} 25$ & 116.86 & $117.9(4)$ \\
\hline H19-C18-H21 & 107.58 & 109.5 & O24-N22-O25 & 118.92 & $121.7(4)$ \\
\hline
\end{tabular}


Table 3

\begin{tabular}{ccccc}
\hline$D-\mathrm{H} \cdots A$ & $D-\mathrm{H}(\AA)$ & $\mathrm{H} \cdots A(\AA)$ & $D \cdots A(\AA)$ & $D-\mathrm{H} \cdots A\left(^{\circ}\right)$ \\
\hline $\mathrm{N} 1-\mathrm{H} 1 \mathrm{~A} \cdots \mathrm{O} 2^{\mathrm{i}}$ & 0.91 & 2.28 & $2.927(5)$ & 127.7 \\
$\mathrm{~N} 1-\mathrm{H} 1 \mathrm{~B} \cdots \mathrm{O} 3^{\text {ii }}$ & 0.91 & 2.04 & $2.848(5)$ & 147.2 \\
$\mathrm{~N} 1-\mathrm{H} 1 \mathrm{C} \cdots \mathrm{O} 3$ & 0.91 & 2.02 & $2.896(5)$ & 162.1 \\
$\mathrm{~N} 1-\mathrm{H} 1 \mathrm{C} \cdots \mathrm{O} 1$ & 0.91 & 2.53 & $3.032(5)$ & 115.4 \\
$\mathrm{C} 2-\mathrm{H} 2 \mathrm{~A} \cdots \mathrm{O} 1^{\text {iii }}$ & 0.99 & 2.59 & $3.342(6)$ & 133.1 \\
$\mathrm{C} 2-\mathrm{H} 2 \mathrm{~B} \cdots \mathrm{O} 2^{\text {iv }}$ & 0.99 & 2.57 & $3.398(6)$ & 141.3 \\
\hline
\end{tabular}

Symmetry codes: (i) $-1 / 2+\mathrm{x}, 1 / 2-\mathrm{y}, \mathrm{z}+1 / 2$; (ii) $\mathrm{x}, \mathrm{y}, 1+\mathrm{z}$; (iii) $1 / 2+\mathrm{x}, 1 / 2-\mathrm{y}, \mathrm{z}+1 / 2$;(iv) $1 / 2+\mathrm{x}, 1 / 2$ $\mathrm{y}, \mathrm{z}+3 / 2$.

Table 4

\begin{tabular}{ccccc}
\hline ER & $\mathrm{H}$ & $\mathrm{C}$ & $\mathrm{N}$ & $\mathrm{O}$ \\
\hline $\mathrm{H}$ & 0.60 & 1.42 & 0.27 & 1.24 \\
$\mathrm{C}$ & & & & 0.16 \\
$\mathrm{~N}$ & & & & 3.64 \\
$\mathrm{O}$ & & & & 0.12 \\
\hline
\end{tabular}


Table 5

\begin{tabular}{|c|c|c|c|c|c|c|}
\hline Interactions & $\rho(r)$ (a.u.) & $\begin{array}{l}\Delta \rho(\mathbf{r}) \\
\text { (a.u.) }\end{array}$ & $\begin{array}{l}\mathbf{H}(\mathbf{r}) \\
\text { (a.u.) }\end{array}$ & G(r) (a.u.) & $\begin{array}{c}\mathrm{V}(\mathbf{r}) \\
\text { (a.u.) }\end{array}$ & $\mathrm{E}_{\text {int }}\left(\mathrm{kJ} \cdot \mathrm{mol}^{-1}\right)$ \\
\hline \multicolumn{7}{|c|}{ Monomer } \\
\hline $\mathrm{N} 1-\mathrm{H} 4 \ldots \mathrm{O} 25$ & 0.0237 & 0.0784 & 0.0017 & 0.0178 & -0.0161 & -20.93 \\
\hline $\mathrm{RCP}$ & 0.0223 & 0.1658 & 0.0076 & 0.0338 & -0.0261 & - \\
\hline \multicolumn{7}{|c|}{ Dimmer } \\
\hline "N43-O46...H4 & 0.0233 & 0.0814 & 0.0020 & 0.0183 & -0.0016 & -2.08 \\
\hline N43-O44...H31 & 0.0051 & 0.0166 & 0.0006 & 0.0035 & -0.0029 & -3.77 \\
\hline N43-O44...H27 & 0.0071 & 0.0250 & 0.0009 & 0.0053 & -0.0044 & -5.72 \\
\hline N47-O50...H2 & 0.0141 & 0.0506 & 0.0017 & 0.0108 & -0.0090 & -11.7 \\
\hline N47-O50...H17 & 0.0047 & 0.0171 & 0.0006 & 0.0036 & -0.0029 & -3.77 \\
\hline N47-O50...H24 & 0.0228 & 0.0800 & 0.0021 & 0.0179 & -0.0158 & -20.54 \\
\hline $\mathrm{RCP1}$ & 0.0223 & 0.1660 & 0.0076 & 0.0338 & -0.0262 & - \\
\hline $\mathrm{RCP} 2$ & 0.0224 & 0.1662 & 0.0076 & 0.0339 & -0.0263 & - \\
\hline NRCP1 & 0.0033 & 0.0151 & 0.0008 & 0.0029 & -0.0021 & - \\
\hline NRCP2 & 0.0039 & 0.0156 & 0.0008 & 0.0031 & -0.0022 & - \\
\hline
\end{tabular}


Table 6

\begin{tabular}{llll}
\hline Parameters & Value & Parameters & Value \\
\hline$\alpha_{\mathrm{xx}}$ & 132.49 & $\beta_{\mathrm{xxx}}$ & 191.01 \\
$\alpha_{\mathrm{xy}}$ & 12.34 & $\beta_{\mathrm{xxy}}$ & -251.86 \\
$\alpha_{\mathrm{xz}}$ & 125.47 & $\beta_{\mathrm{xyy}}$ & 97.33 \\
$\alpha_{\mathrm{yy}}$ & 9.85 & $\beta_{\mathrm{yyy}}$ & -209.37 \\
$\alpha_{\mathrm{yz}}$ & -2.71 & $\beta_{\mathrm{xxz}}$ & -77.56 \\
$\alpha_{\mathrm{zz}}$ & 94.11 & $\beta_{\mathrm{xyz}}$ & 28.45 \\
$\alpha_{\text {total }}($ esu $)$ & $17.39 \times 10^{-24}$ & $\beta_{\mathrm{yyz}}$ & -14.79 \\
\hline$\mu_{\mathrm{x}}$ & 12.14 & $\beta_{\mathrm{xzz}}$ & 24.89 \\
$\mu_{\mathrm{y}}$ & -7.31 & $\beta_{\mathrm{yzz}}$ & -43.31 \\
$\mu_{\mathrm{z}}$ & -2.43 & $\beta_{\mathrm{zzz}}$ & -37.70 \\
$\mu_{\text {total }}($ Debye $)$ & 14.38 & $\beta($ esu $)$ & $5252.35 \times 10^{-33}$ \\
\hline
\end{tabular}

However, $\alpha$ and $\beta$ values of the Gaussian output are in atomic units (a.u.), so they have been converted into electronic units (esu) $)\left(\alpha ; 1\right.$ a.u. $=0.1482 \times 10^{-24} \mathrm{esu}, \beta ; 1$ a.u. $\left.=8.6393 \times 10^{-33} \mathrm{esu}\right)$.

Table 7

\begin{tabular}{lc}
\hline & Gas \\
\hline $\mathrm{E}_{\text {HOMO }}(\mathrm{eV})$ & -7.10 \\
$\mathrm{E}_{\text {LUMO }}(\mathrm{eV})$ & -1.76 \\
$\Delta \mathrm{E}_{\text {HOMO-LUMO }}(\mathrm{eV})$ & 5.34 \\
Electronic affinity $\mathrm{A}(\mathrm{eV})$ & 1.76 \\
Ionization potential I $(\mathrm{eV})$ & 7.10 \\
Chemical hardness $\eta(\mathrm{eV})$ & 2.67 \\
Softness S $(\mathrm{eV})$ & 0.38 \\
Chemical potentiel $\mu(\mathrm{eV})$ & -4.43 \\
Electronecativity $\chi(\mathrm{eV})$ & 4.43 \\
Electrophilicity $\psi(\mathrm{eV})$ & 3.68 \\
\hline
\end{tabular}


Table 8

\begin{tabular}{|c|c|c|c|}
\hline $\begin{array}{l}\text { Experimental } \\
\text { IR }\end{array}$ & $\begin{array}{c}\text { Theoretical } \\
\text { IR }\end{array}$ & $\mathrm{I}^{\mathrm{i}}$ & Vibrational assignments (\% PED) \\
\hline 3447 & 3549 & 12.58 & $v \mathrm{NH}(100)$ \\
\hline 3416 & 3471 & 3.32 & $v \mathrm{NH}(99)$ \\
\hline 3218 & 3182 & 17.42 & vNH (98) \\
\hline 3217 & 3161 & 19.54 & $\vee \mathrm{CH}(98)$ \\
\hline 3217 & 3160 & 4.63 & $v \mathrm{CH}(98)$ \\
\hline 2976 & 3155 & 0.23 & $v \mathrm{CH}(98)$ \\
\hline \multirow{6}{*}{$\begin{array}{l}3050 \\
3050 \\
3000\end{array}$} & 3108 & 12.71 & $v \mathrm{CH}(92)$ \\
\hline & 3078 & 15.80 & $v \mathrm{CH}(94)$ \\
\hline & 3068 & 14.62 & $v \mathrm{CH}(90)$ \\
\hline & 3024 & 26.24 & $v \mathrm{CH}(84)$ \\
\hline & 3024 & 33.55 & $v \mathrm{CH}(91)$ \\
\hline & 2341 & 2536.19 & $v \mathrm{OH}(94)$ \\
\hline 1762 & 1726 & 117.89 & $v \mathrm{ON}(46) \quad \delta \mathrm{HON}(30)$ \\
\hline 1610 & 1650 & 46.16 & $\nu \mathrm{CC}(42) \tau \mathrm{HNHC}(16) \quad \delta \mathrm{HCC}(12)$ \\
\hline 1610 & 1642 & 19.37 & $\nu$ CC (24) $\tau \mathrm{HNHC}(38)$ \\
\hline \multirow[t]{3}{*}{1610} & 1628 & 7.07 & $v \mathrm{CC}(67) \quad \delta \mathrm{HCH}$ \\
\hline & 1535 & 523.40 & $v \mathrm{ON}(45) \quad \delta \mathrm{HON}(22)$ \\
\hline & 1525 & 6.19 & $\delta \mathrm{HCC}(51) \quad \delta C C C(20)$ \\
\hline \multirow{6}{*}{$\begin{array}{l}1516 \\
1505\end{array}$} & 1516 & 11.74 & $\delta \mathrm{HCH}(85)$ \\
\hline & 1499 & 10.53 & $\delta \mathrm{HCH}(54) \tau \mathrm{HCCC}(17)$ \\
\hline & 1491 & 7.52 & $\delta \mathrm{HCH}(85)$ \\
\hline & 1459 & 2.88 & $\delta \mathrm{HCH}(44)$ \\
\hline & 1419 & 20.45 & $\tau \mathrm{HCHN}(28) \quad \delta \mathrm{HCH}(37)$ \\
\hline & 1416 & 9.58 & $\tau \mathrm{HCHN}(14) \quad \delta \mathrm{HCH}$ \\
\hline \multirow[t]{10}{*}{1380} & 1350 & 0.56 & $\delta \mathrm{HCC}(75) \quad v \mathrm{CC}(12)$ \\
\hline & 1340 & 1.96 & $\tau \mathrm{HCHN}(10) \quad v \mathrm{CC} 42 \quad \delta \mathrm{HCH}(13)$ \\
\hline & 1315 & 545.41 & $v$ ON $80 \delta$ ONO -10 \\
\hline & 1291 & 13.02 & $v \mathrm{CC}(12) \delta \mathrm{HCH}(27) \quad \tau \mathrm{HCHN}(12)$ \\
\hline & 1270 & 4.20 & $v \mathrm{CC}(55)$ \\
\hline & 1220 & 98.22 & $\tau \mathrm{HNHC}(10) \quad \delta \mathrm{NHO}(46) \quad \delta \mathrm{HNH}(20)$ \\
\hline & 1200 & 1.34 & $v \mathrm{CC}(16) \delta \mathrm{HCC}(60)$ \\
\hline & 1189 & 8.16 & $\delta \mathrm{HCC}(30) v \mathrm{CC}(12)$ \\
\hline & 1161 & 24.67 & $\delta \mathrm{HNC}(32)$ \\
\hline & 1121 & 2.16 & $\delta \mathrm{HCH}(28) \quad v \mathrm{CC}(46)$ \\
\hline \multirow[t]{6}{*}{1096} & 1065 & 26.42 & $\tau \mathrm{HCHN}(24) \quad v \mathrm{CC}(10) \quad \delta \mathrm{HNH}(14)$ \\
\hline & 1064 & 7.16 & $\delta \mathrm{HCC}(67) \tau \mathrm{HCCC}(10)$ \\
\hline & 1016 & 0.97 & $v \mathrm{CC}(14) \quad \delta \mathrm{CCC}(56)$ \\
\hline & 1013 & 9.82 & $v \mathrm{CC}(10) \tau \mathrm{HCCC}(40)$ \\
\hline & 1003 & 30.24 & $v \mathrm{NC}(71)$ \\
\hline & 991 & 0.37 & $\tau \mathrm{HCCH}(88)$ \\
\hline \multirow[t]{3}{*}{1044} & 959 & 232.24 & $v \mathrm{ON}(64) \quad \delta \mathrm{ONO}(27)$ \\
\hline & 929 & 6.75 & $\tau \mathrm{HCCC}(62)$ \\
\hline & 925 & 18.85 & $v \mathrm{CC}(38)$ \\
\hline
\end{tabular}




\begin{tabular}{|c|c|c|c|}
\hline \multirow{3}{*}{887} & 907 & 10.21 & $\tau \mathrm{HCCC}(83)$ \\
\hline & 896 & 31.03 & $v \mathrm{CC}(14) \quad \delta \mathrm{HNH}(12)$ \\
\hline & 800 & 36.74 & $\tau \mathrm{HCCC}(73)$ \\
\hline 827 & 794 & 9.90 & $\delta$ OOON (99) \\
\hline 819 & 740 & 11.26 & $v \mathrm{CC}(17) \quad \delta \mathrm{CCC} 13$ \\
\hline 723 & 717 & 18.53 & $\tau \operatorname{CCCC}(61)$ \\
\hline 710 & 695 & 5.76 & $v \mathrm{ON}(32) \quad \delta \mathrm{ONO}(64)$ \\
\hline & 671 & 8.28 & $\delta \mathrm{ONO}(57) \quad \delta \mathrm{HNH}(10)$ \\
\hline 554 & 614 & 14.41 & $\delta$ ONO (11) $\tau \mathrm{CCCC}(17) \quad \delta \mathrm{CCN}(21)$ \\
\hline \multirow{5}{*}{470} & 538 & 0.73 & $v \mathrm{CC}(14) \quad \delta \mathrm{CCC}(58)$ \\
\hline & 519 & 3.15 & $\tau \operatorname{CCCC~}(20) \quad \delta \operatorname{CCC}(43)$ \\
\hline & 480 & 20.20 & $\delta \mathrm{HNH}(38)$ \\
\hline & 448 & 9.04 & $\tau \mathrm{CCCC}(66)$ \\
\hline & 400 & 0.59 & $\delta \mathrm{CCC}(76)$ \\
\hline
\end{tabular}

$\mathrm{I}^{\mathrm{i}}$ : infrared intensity $\left(\mathrm{km} \cdot \mathrm{mol}^{-1}\right), v, \delta$ and $\tau$ denote stretching, in-plane and Out-of-plane deformation and torsion modes, respectively. PED: potential energy distribution data are taken fromVEDA4. 